This item was submitted to Loughborough's Research Repository by the author.

Items in Figshare are protected by copyright, with all rights reserved, unless otherwise indicated.

\title{
Talking cognition: mapping and making the terrain
}

PLEASE CITE THE PUBLISHED VERSION

http://www.cambridge.org/gb/knowledge/isbn/item1167951/?site_locale=en_GB

PUBLISHER

(c) Cambridge University Press

VERSION

AM (Accepted Manuscript)

LICENCE

CC BY-NC-ND 4.0

REPOSITORY RECORD

Potter, Jonathan, and Hedwig te Molder. 2019. "Talking Cognition: Mapping and Making the Terrain”. figshare. https://hdl.handle.net/2134/9357. 
This item was submitted to Loughborough's Institutional Repository (https://dspace.lboro.ac.uk/) by the author and is made available under the following Creative Commons Licence conditions.

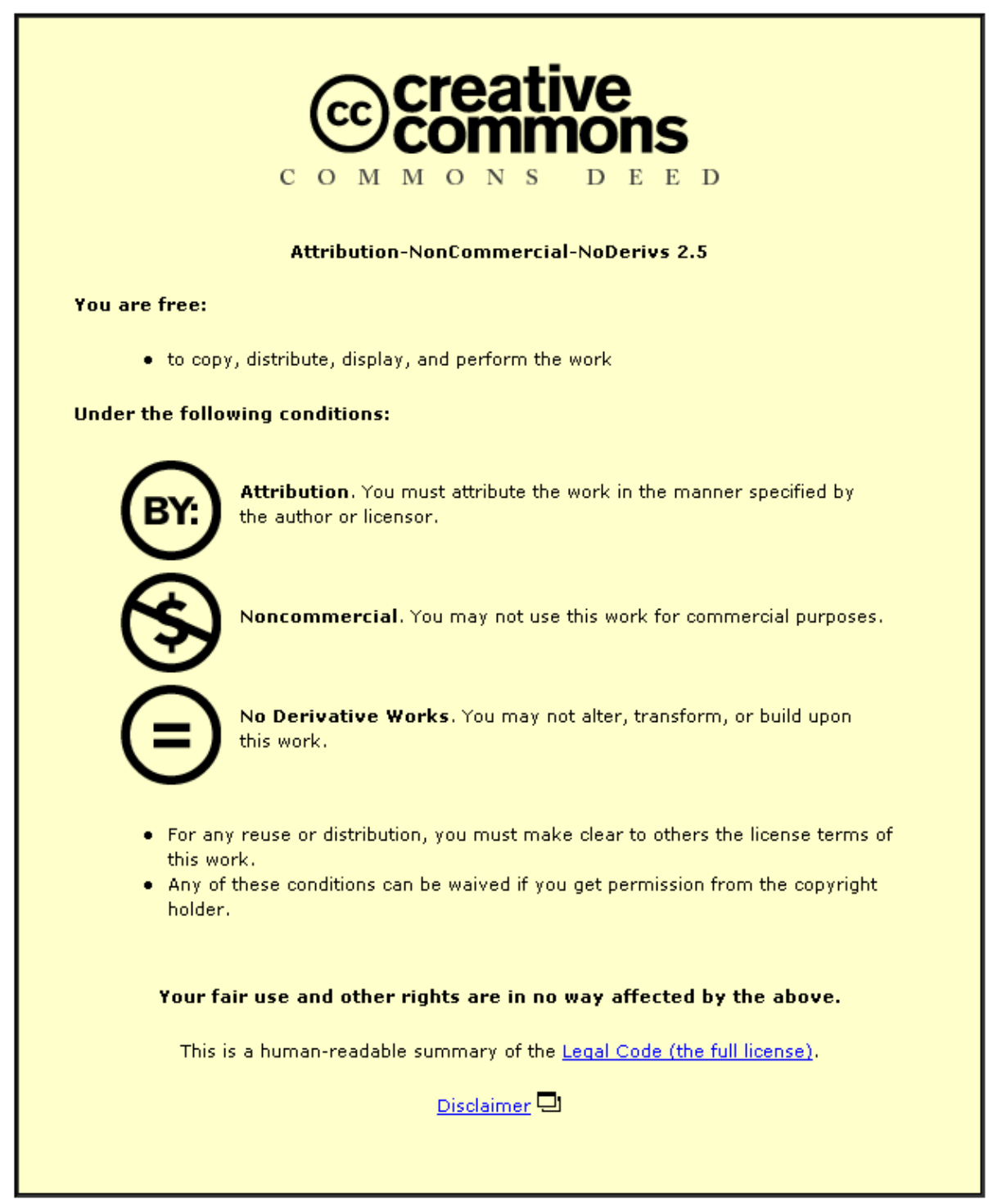

For the full text of this licence, please go to: http://creativecommons.org/licenses/by-nc-nd/2.5/ 


\title{
1 Talking cognition: Mapping and making the terrain
}

\author{
Jonathan Potter \& Hedwig te Molder
}

\section{Overview}

This book addresses issues of talk and cognition. For the first time some of the world's experts on interaction analysis have been brought together to consider the nature and role of cognition. They address the question of what part, if any, cognitive entities should play in the analysis of interaction. They develop different answers. Some are consistent with current thinking in cognitive psychology and cognitive science; others are more critical, questioning the idea that cognition is the obvious and necessary start point for the study of human action.

The question of the relation of language and thought has been a central one in cognitive and developmental psychology for more than 30 years. For the contributors here the focus is not on language as it is traditionally understood but rather on talk or, even more specifically, on talk-in-interaction. That is, not on language as an abstract set of words, meanings, or a system of contrasts as it has usually been conceived, but talk as a practical, social activity, located in settings, occurring between people, used in practices. This approach has significant implications for the way traditional issues of cognition are treated. Talk and cognition have been brought together only rarely in the past, and often for particular purposes local to one discipline. However, there are some important precursors to the current enterprise, and we will describe them in detail below. 
It is worth noting at the outset that because of its interdisciplinary focus this book is likely to have audiences with different levels of knowledge, understanding and expectation. In particular, we hope it will be of interest to at least three groups of researchers. First, it will be of interest to those people whose primary topic is the study of interaction. The issue of how (if at all), or in what way, cognition figures in interaction is a live and complex one with important implications for how analysis can be done and what might be possible. Second, it will be of interest to discursive psychologists and the wider community of social psychologists who have attempted to develop an alternative to traditional social cognitive perspectives. For them, it will refine several of the issues and highlight the value of considering them in terms of natural interaction. Third, we hope the book will be interesting to the very broad community of cognitive scientists. Cognition has been understood in a wide range of ways in this community (some of which we will describe below) but only rarely has the start point been research on natural interaction.

The contributors to this book are some of the foremost analysts of natural interaction in the world. Although each has his or her individual take on things, they mostly draw on one or more of the connected approaches of ethnomethodology, conversation analysis and discursive psychology. We will have more to say about these approaches later. For the moment we will use thumbnails.

Ethnomethodology is an approach to the methods that people use for making sense of, and accomplishing the order of, their social worlds. It highlights the use of ad hoc, situation specific procedures to generate order. Most recently its emphasis has been on the way action must be understood in terms of the full, embodied, practical specifics of its setting. The key figure in the development of ethnomethodology is the sociologist Harold Garfinkel (Garfinkel, 1967, 2002). In this collection Michael Lynch, David Bogen and Jeff Coulter have been most associated with this perspective. 
Conversation analysis is the study of natural talk as a medium for action and interaction. A very large body of studies from a conversation analytic perspective have been done on both everyday and institutional talk. Conversation analysis has its origins in the lectures of the sociologist Harvey Sacks (now published as Sacks 1992), and the work of his colleagues Gail Jefferson and Emanuel Schegloff (e.g. Sacks, Schegloff and Jefferson, 1974). Many of the contributors to this collection have a broadly conversation analytic perspective, including Bob Sanders, Anita Pomerantz, Douglas Maynard, Nora Schaeffer, Robert Hopper, John Heritage, Paul Drew, and Robin Wooffitt. This predominance reflects the way conversation analysis has become one of the most powerful and empirically cumulative fields in the study of interaction.

Discursive psychology is an approach that considers psychology as an object in and for interaction. That is, it focuses on how psychological categories and constructions are used by people in everyday and institutional settings. While ethnomethodologists and conversation analysts have mainly worked within sociology and have often found issues of cognition rather peripheral, discursive psychologists have mainly worked within psychology and consequentially have a longer history of addressing these issues. Key figures in the development of discursive psychology are Derek Edwards and Jonathan Potter (Edwards, 1997; Edwards \& Potter, 1992). In this collection Derek Edwards, Hedwig te Molder, Jonathan Potter and Robin Wooffitt (again) are most associated with this approach.

There is considerably more theoretical and analytic homogeneity here than even this listing of just three approaches suggests. Both conversation analysis and discursive psychology pick up from and develop themes from ethnomethodology. Moreover, for the most part all three approaches emphasise that:

a) Talk is a medium of action.

b) Talk is locally and situationally organized. 
c) The point of view of the interactant is basic to understanding talk-in-interaction.

d) The primary analytic approach is empirical study of natural interaction.

These features have led researchers in this area in a very different methodological direction to most cognitive scientists. In particular, the emphasis on action, context and natural talk leads away from working with either experimental manipulations or invented and decontextualized examples. It is worth emphasising, however, that although this body of work has provided a basis for doubt about those methods it was not, on the whole, this that led researchers in the direction they took. The tradition of work in conversation analysis evolved out of a combination of novel theorizing about interaction stimulated by Garfinkel and Sacks, and the development of tape recording technology that allowed conversation to be studied in a way previously impossible. Having developed a powerful analytic approach for working directly with records of interaction, experimental simulations of interaction seemed to be of limited value and potentially misleading.

The broad sweep of the arguments here means that we will inevitably not be able to cover all potentially relevant literature. For example, we will not cover the writing of critics of cognitive approaches such as Gergen, Harré and Shotter (e.g. Gergen, 1994, 1999; Harré, 2002; Shotter, 1983) who work largely with theoretical and conceptual analysis. Examples of such work are collected together in Still and Costall (1991), and include a number of arguments inspired by the work of Gibson (1979). This work has some significant virtues, yet it does not provide for the focused investigation of questions about cognition in interaction that is developed in the chapters collected here.

In the rest of this introductory chapter we will try to accomplish a series of things. First, we will describe some of the questions that the book is intended to illuminate. Second, we will consider some of the historical, conceptual and philosophical features of the notion of cognition, including its relation to language. Third we will characterise some of the key 
features of the set of perspectives that have been developed in the broad field of cognitive science, and cognitive psychology more specifically. This will introduce a set of issues that will help to explicate the relevance of work in interaction described later in this chapter, and in the chapters that follow. It is also intended to highlight the variety and complexity of what cognitive researchers have achieved and what points of entry into this work there might be for interaction researchers. Fourth, we will describe the way issues of cognition have been dealt with in existing work on interaction, concentrating particularly on ethnomethodology, conversation analysis and discursive psychology. Fifth, and finally we will provide a synoptic overview of the contributions to this book ending with some comments on future progress.

\section{Questions of Cognition and Interaction}

The questions addressed in this collection are derived from empirical studies of interaction. The book is intended to extend and clarify issues to do with the nature and role of cognitive entities in interaction analysis. However, it is precisely that focus that makes for some interesting and potentially novel implications for more traditional cognitive psychologists and cognitive scientists.

The papers in this collection are relevant to a range of questions. Some of the most important are:

- How does cognition figure in the analysis of interaction? Alternatively, can (and should) such analysis be done without recourse to cognitive notions? 
- If speakers draw on cognitive notions, what is their status? That is, what kind of thing is cognition for participants in interaction? How is it invoked, described and oriented to by speakers in the course of interaction?

- In the strongest case, is interaction only explicable in terms of a set of cognitive precursors (cognitivism)? How far can these precursors reflect lay notions and orientations of conversational participants and how far must they be derived from technical analyses?

- How does interaction research throw light on continuing questions about the possible relations between mental terms and cognitive entities?

- What implications does the exploration of these questions have for experimental work in cognitive science?

These are complicated questions that raise fundamental issues about method, theory and the nature of psychology. The aim is to clarify them, underscore their significance, and show the way towards their answers. Some papers consider a cognitive level of analysis indispensable (e.g. Sanders). Some papers suggest that interaction analysis can reveal the role of particular kinds of cognitive entities (e.g. Schaeffer \& Maynard, Drew, Pomerantz). Some suggest that analysis should respecify cognitive notions in interactional terms (Lynch \& Bogen, Wooffitt). Some develop an agnostic approach (Hopper) or wish to consider cognitive notions in terms of topics or orientations in participants' talk (Edwards \& Potter). One paper (Coulter) provides a trenchant (and conceptually based) critique of the whole enterprise of cognitive science. 


\section{Cognition as an Object in Language and Philosophy}

Characterizing contemporary cognition and its development is not an easy task. Cognitive science is now a broad and heterogeneous intellectual field cutting across the disciplines of psychology, computer studies, anthropology, linguistics, neuroscience, and philosophy. It mixes highly technical conceptual and metaphysical analyses with issues that arise out of programming and domain-specific applied work on computer systems and human factors. There is no single notion of cognition cutting across this field. Histories in textbooks and encyclopaedias cite a wide range of philosophers cited as key figures (including Plato and Aristotle, of course) as well as a varied selection of $19^{\text {th }}$ and $20^{\text {th }}$ Century psychologists and figures from other disciplines. Let us start with the dictionary.

The term cognition

The Oxford English Dictionary (2002) helpfully distinguishes an everyday sense of cognition from a more philosophical notion:

1. a. The action or faculty of knowing; knowledge, consciousness; acquaintance with a subject. (Obs.)

1447 O. Bokenham Seyntys (1835) 154 Illumynyd she is wyth clere cognycyoun In hyr soule.

1528 Lyndesay Dream 577 Filicitie they had Inuariabyll, And of his Godhed cleir cognitioun.

1604 T. Wright Passions v. 237 With conscience and perfit cognition of innocencie.

1606 Shakes. Tr. \& Cr. v. ii. 63, I will not be my selfe, nor haue cognition Of what I feele.

1682 Sir T. Browne Chr. Mor. (1756) 106 A retrograde cognition of times past.

1796 Burney Mem. Metastasio II. 389 Tasting the first aliments of scientific cognition.

b. Apprehension, perception. (nonce-use.)

1822 Lamb Elia Ser. i. iii. (1865) 34 In thy cognition of some poignant jest. 
2. Philos. a. The action or faculty of knowing taken in its widest sense, including sensation, perception, conception, etc., as distinguished from feeling and volition; also, more specifically, the action of cognizing an object in perception proper.

1651 Stanley Poems 231 This Divines call intellectual intuitive cognition.

1690 Locke Hum. Und. iv. iii. §6 Finding not Cognition within the natural Powers of Matter.

1847 Lewes Hist. Philos. (1867) I. Introd. 113 A faculty of cognition a priori.

1879 Adamson Philos. Kant 45 The several elements which, according to Kant, make up the organic unity of Perception or real Cognition.

b. A product of such an action: a sensation, perception, notion, or higher intuition.

1819 Shelley Peter Bell III, 473 note, Peter's progenitor... seems to have possessed a 'pure anticipated cognition' of the nature and modesty of this ornament of his posterity.

1856 Meiklejohn tr. Kant's Krit. P.R. 79 The fact that we do possess scientific a priori cognitions, namely, those of pure mathematics and general physics.

1873 H. Spencer Princ. Psychol. I. iii. viii. 369 With purely intellectual cognitions... also with... moral cognitions.

1881 J. H. Stirling Text-bk. Kant 468 Let a cognition be intellectually what it may, it is no cognition proper, it is not properly Knowledge, unless and until it have an actual perceptive application.

A few things are worth noting about these definitions and the examples quoted. First, an idea of cognition residing inside the person (e.g. 'in hyr soule' from 1447) goes back several hundred years. Second, both the everyday and philosophical senses of the term have an epistemic element. Cognition is related to knowledge; it is cognition of something. This reflects the Latin root of cognition as getting to know, acquaintance, knowledge. The move from Latin to English, then, can be understood as a move from an objective to a subjective view of knowledge. Third, cognition can be of something which is itself 'psychological' (obviously the idea of psychology must be used with caution here or we will end in vicious circularity). Thus there is 'perfit cognition of innocencie' or 'cognition Of what I feele'. 
Alternatively, it can be something 'outside' the person, such as 'times past'. Fourth, note that the philosophical senses of cognition reflect the argument between empiricists and rationalists, with cognition requiring 'actual perceptive application' versus the idea of 'a priori cognitions' of 'mathematics and general physics'. Finally, we can see the linking of cognition to 'perception' that is at the heart of much modern cognitive psychology.

\section{Philosophical precursors to cognitive science: Descartes and Locke}

The modern philosophical account of cognition is crucially dependent on the work of two $17^{\text {th }}$ Century philosophers: Rene Descartes and John Locke. Descartes is, of course, the philosopher who most famously helped shape modern thinking about the nature and role of cognition. He addressed epistemic issues about truth and knowledge through considering what could be fallible in the quest for what could be indubitable. For him, the world of objects might not exist because, after all, they might be the vivid illusions of dreams. Yet there has to be an 'I' doing that thinking, whether true or illusory, and that could be the foundation for knowledge. As he put it:

It was absolutely essential that the 'I' who thought this should be somewhat, and remarking that this truth 'I think therefore I am' was so certain and so assured that all the most extravagant suppositions brought forward by the sceptics were incapable of shaking it (Descartes, 1970: 101)

We might not be able to see how things are in the outer world, but we do know their appearance in our inner world. Nothing, in the end, is better known to the mind than itself. By inventing a superior class of inner perceptions, Descartes ingeniously attempted to surmount the agonizing problem of the outer world's deceitfulness.

As Rorty (1979) argues in his critical analysis of the history of Western philosophy, the notion of mind does not emerge in philosophical debates until Descartes. For the Greeks, 
the essential matter was how to obtain an unmediated picture of reality, that is, how to see reality directly without being distracted by any of its mere appearances. After Descartes, knowledge was still understood in terms of perception, but now the eye as the central metaphor for acquiring knowledge had been exchanged for another powerful image: the mirror. Knowledge of the world was no longer directly available, but only through a mirror in which nature is being reflected indirectly. As Rorty put it: "The question "How can I escape from the realm of appearance?" was replaced by the question "How can I escape from behind the veil of ideas?"' (1979: 160).

Part of Descartes' legacy to cognitive science is a basic mind/body dualism. In his writing it is possible to see this as required to manage a problem of his own making. Having established the special nature of the mind, how can it make contact with anything else? Descartes' rather ad hoc pineal gland solution was an early attempt to solve a problem that is still very much alive in different ways in contemporary cognitive science.

Descartes set the scene for a treatment of perception as the mind's mirror on the world, with mind as the solid foundation for knowledge to be built on. Departing from earlier Greek and medieval conceptions, he developed the notion of an idea that would apply exclusively to the content of the human mind (Kenny, 1967). Some fifty years later Locke drew on this same notion of an idea in his account of the nature of knowledge and what has become a classic picture of the working of language.

Locke viewed ideas as a basic currency of thinking and therefore philosophy. These ideas came from 'sensation and reflection'. This is the way the famous white paper (tabula rasa) comes to be filled in its 'almost endless variety'. Knowledge in turn comes either directly from experience or, in a move echoed in modern cognitivism, 'the internal operations of our minds perceived and reflected on by ourselves, is that which supplies our understandings with all the materials of thinking' (Locke, Bk I, Ch. I, pt. 2). Simple ideas 
come through sensation to a passive mind. Then activities of mind turn these into complex ideas through basic processes of combination, comparison or separation. As he put it:

The acts of the mind, wherein it exerts its power over its simple ideas, are chiefly these three: (1) Combining several simple ideas into one compound one; and thus all complex ideas are made. (2) The second is bringing two ideas, whether simple or complex, together, and setting them by one another, so as to take a view of them at once, without uniting them into one; by which way it gets all its ideas of relations. (3) The third is separating them from all other ideas that accompany them in their real existence: this is called abstraction: and thus all its general ideas are made (Locke, Bk. II, Ch. XII, pt. 1).

Mind here is an agent processing information much as, in more refined and technical forms, it appears in contemporary cognitive psychology.

Locke's reasoning about mind is bound up with his account of language. He developed what Roy Harris (1988) has described as a telementation account of language. In this account language is understood as a conduit for communicating ideas from one mind to another.

Words are sensible signs, necessary for communication of ideas. Man, though he have great variety of thoughts, and such from which others as well as himself might receive profit and delight; yet they are all within his own breast, invisible and hidden from others, nor can of themselves be made to appear. The comfort and advantage of society not being to be had without communication of thoughts, it was necessary that man should find out some external sensible signs, whereof those invisible ideas, which his thoughts are made up of, might be made known to others (Locke, Bk. III, Ch. II, pt. 1, italics in original). 
Note here the emphasis on ideas hidden invisibly inside the person, and the role of language being to make them visible (Coulter develops Harris's argument about telementation in his contribution to this volume).

Words are secondary to ideas for Locke. Indeed, the first use of words is for recording thoughts, rather like a Dictaphone might be used to record a letter. The second use is for communicating thoughts. Because of their conventional and arbitrary nature (Locke prefigures Saussure here) he sees words as an imperfect way of transmitting ideas. The recipient may well find them doubtful and uncertain as cues to the precise ideas of the speaker. In contrast, if you are recording your thoughts for yourself using words your record can be perfect:

Any words will serve for recording. As to the first of these, for the recording our own thoughts for the help of our own memories, whereby, as it were, we talk to ourselves, any words will serve the turn. For since sounds are voluntary and indifferent signs of any ideas, a man may use what words he pleases to signify his own ideas to himself: and there will be no imperfection in them, if he constantly use the same sign for the same idea: for then he cannot fail of having his meaning understood, wherein consists the right use and perfection of language (Locke, Bk. III, Ch. IX, pt. 2, italics in original).

Language, then, becomes an aid to thinking and can enable our own memories and ideas to be captured, yet can only capture those of others in an indistinct manner.

Rorty (1980) has argued that Descartes and Locke virtually invented the modern idea of the human mind. In Greek philosophy there had been no easy way to distinguish what might later be called 'states of consciousness' from objects and events in the world. Descartes extended the notion of thought so that it would cover many of what we would come to think of as cognitive psychological terms: doubting, understanding, imagining and so 
on. Locke extended these ideas into a quasi-scientific programme of considering the generation and composition of ideas and the processes this involved. Words were left as imperfect traces of those inner ideas.

We do not want to suggest that Descartes and Locke are the only important philosophical contributors to ideas about cognition. However, they lay out many of the features that stayed in place until the sorts of critique of this picture of mind came from linguistic philosophers such as Ryle and Wittgenstein in the $20^{\text {th }}$ Century. They still have a central role in modern cognitive science. Some of these issues are explored below, particularly in Coulter's chapter. For the moment we will move away from philosophy to consider the development of modern cognitive science.

\section{Modern Cognitive Science}

Histories of contemporary cognitive science identify the key dates as just following World War II. For example, Gardner's (1985) excellent overview suggests the so called 'Hixon symposium' of 1948 as the setting where a number of key figures who had developed their thinking in different fields of war work came together. Many features of modern cognitive science have their origin in work on missile guidance systems, problems of people using complex apparatus such as cockpit displays, and the new science of computing. Technical advances here went in concert with the major social upheavals of the war, and challenges to old orthodoxies. The most important orthodoxy to be challenged was that of the behaviourist tradition that had dominated for the three decades up to the war, particularly in North America. Its role as the position to be countered can be seen in the title of McCulloch's contribution to the symposium: 'Why the Mind Is in the Head'. The 
capitalization of 'Is' here went against the general behaviourist caution about the attribution of inner entities. Gardner describes this title as provocative in 1948 - yet within thirty years the success of cognitive science would make it as orthodox as what came before.

The five decades that have followed have been a period of furious development for cognitive science that has grown up with the evolution of integrated circuits, computing and the Internet. For us the interest is in the nature of the cognitive in cognitive science. What kinds of things are described as cognitive processes and cognitive states? What styles of explanation are characteristic in cognitive science? Our overview of cognitive science is not intended to be comprehensive. Instead we will highlight some central moments and features of the area.

Information theory and artificial intelligence: Shannon, Turing and Marr

Theoretical and technological advances in the mid $20^{\text {th }}$ Century led to the development of information theory. Shannon's crucial insight was that the states of an electronic switch (on/off) could be treated as equivalent to logical propositions (true/false). This was refined into the notion of a bit of information, that is, the information required to reduce future uncertainty by choosing one of two equal options. This was crucial in the development of programming languages that would run on computers, where the transistors (on/off switches) in integrated circuits would allow large, and (with time) enormous, amounts of information to be 'processed' (Gardner, 1985).

Information here is an abstraction. It has been separated from both particular languages such as English or French, and also from particular processing or communication systems. It can be transmitted via wire or radio, and processed by different kinds of computers. Crucially it was possible to start thinking of human brains as processors of 
information. This, in turn, could allow the old behaviourist concepts of stimulus and response to be transformed into new information processing concepts of input and output.

If human brains could be treated as processors of information like computers, could the reverse be true? Could computers be treated like brains, or, more pertinently, can they think? Alan Turing's (1950) famous and influential answer to this question is to turn it into a practical rather than an abstract or philosophical question. The Turing test involves an imaginary interrogator who asks questions of an agent in another room via a teleprinter. The job for the interrogator is to find out whether she is talking to a man or a machine. The job for the machine is to answer questions as if they were a man. They can be evasive, playful, or whatever. Here Turing imagines A as a machine pretending to be a person:

Q: $\quad$ Please write me a sonnet on the subject of the Forth Bridge.

A: Count me out on this one. I could never write poetry. (Turing, 1950: 234).

The key point about this test is that if the computer passed, if it were programmed in a way that convincingly imitated a person, then there were no good grounds for saying it was not thinking (Turing dismissed a lot of what he took to be poor grounds, such as that it did not have a soul, machines can't be creative). We can note at this point that issues of personhood are foregrounded, but issues of what interaction is, and how language operates in activities such as imitation are taken for granted.

Whether or not cognitive scientists accepted the full implications of the Turing test, they increasingly used metaphors from computing and information processing for understanding human cognition - input and output, hardware and software, storage, programming and so on are commonplace.

As Gardner (1985) notes this has led to continued disputes on how strongly to treat the hypothesis of artificial intelligence. On the one hand, the weak view of artificial 
intelligence treated programming as a way of exploring potential ways in which humans could solve problems or process information. On the other, the strong view suggested that programs are intelligent in themselves, or even that they have their own cognitive states. Searle's (1980) so-called Chinese room argument was designed to criticise such an idea (in a playful inversion of the Turing test).

More directly interesting for our current purposes is not the question whether machines can be programmed to think, but whether a programmed machine that can duplicate human skills is operating in the same way as the human. That is, should we expect to find some underlying psychological correlate of the programming? This kind of question became most refined in the influential work of the neuroscientist David Marr. For us Marr is important not just because he is one of the most important figures in cognitive science, but because his work highlights some of the very different ways in which notions of cognitive processes and entities are understood.

Marr worked on visual perception, but his arguments are taken to have more general implications for cognitive science. In his research he argued that to understand the visual system it is necessary to work with different levels of analysis (Marr, 1982 is the central reference here). The first level is that of computational theory. This specified the goals and functions of the system. For example, one of the things that the visual system will need to do is translate two-dimensional images from each eye into a single three-dimensional image. This might involve a range of more complex functions. The second level is that of representation and algorithm. What kinds of procedures might operate on the images to render them into three-dimensions? What kind of programs and representations would be required? The third level is that of hardware implementation. Experimental work will attempt to discover organizations of axons and visual neurons that might be the systems for processing such information about stereoscopic vision. The success of work such as Hubel 
and Wiesel (1977) on the early processing of visual information in the eye and Lettvin et al. (1959) on specialised receptors in the neurophysiology suggested that more sophisticated processing structures might exist. For Marr research is a two way process, where computational theory and its representations might guide studies of physiology, but studies of physiology might suggest alternative algorithms and, ultimately, computational theories.

Marr's theory shows how early ideas about information processing and metaphors of the mind and brain as sophisticated computers have been developed since Turing and Shannon's time. In particular, he suggests that particular organizations of brain physiology might be designed to do specific jobs. Note also that Marr's work is giving a central place to the operation of computer programs on representations. The centrality of modularity and representations is something well established in much of recent cognitive science.

Marr's division into three levels is only one way of breaking things up. For example, it is conventional in cognitive psychology to distinguish a rather different three levels of information processing: mental, cognitive and neural (e.g. Best, 1999). The mental level of processing is focused on things that people are conscious or aware of how people manipulate images or ponder problems in maths. The cognitive level of analysis is focused on processes of analysis that may not be part of people's consciousness. The neural level is the actual operations of neurons, ganglions and so that perform the tasks that are involved in the cognitive and mental processes.

\section{Linguistics as a vision of competence: Chomsky and Skinner}

In Gardner's (1985) history of cognitive science he traces the significance of the linguist Noam Chomsky's work for cognitive science back to the MIT symposium on information theory of 1956. Chomsky impressed others with the formal precision of his work. He was not just offering a new theory of language, but changing the whole way in 
which language should be understood and studied. His review of Skinner's (1957) behaviourist account of language was widely treated as devastating and providing an important impetus to the establishment of a cognitive science as the successor to behaviourism.

Chomsky's (1959) review argued that behaviourist stimulus-response models of language learning could not account for the creativity of language. People can and do produce unique but also grammatical utterances for which there is no plausible reinforcement history. Moreover, he noted that it is particularly unclear what stimulus might be relevantly eliciting any particular linguistic response. The stimulus-response account starts to become empirically empty. Chomsky encouraged a move away from the strongly empirically based work of Skinner toward an approach much more guided by theory. Indeed, he emphasised the power of people's intuitions about language, and particularly its grammatical form, suggesting that in many cases empirical work was not necessary to check claims. At the epistemological level, this was backed up by a move to a more nativist concept of language to counter Skinner's relentlessly empiricist image of language being learned through behavioural conditioning. He suggested that all of us have an innate Language Acquisition Device (LAD). This enables a child learn a particular language for the first time through hypothesis testing backed by knowledge of human universals. In this way the child could arrive at the specific grammar appropriate for the particular language in her culture (Chomsky, 1965).

Let us stand back and tease out some features of Chomsky's approach that have implications here. The first is that Chomsky's critique of Skinner's and others' approaches to language emphasised the importance of grammar and grammatical universals. In criticising both behavioural approaches and then current linguistic orthodoxy he redefined what is essential about language. This is seen most powerfully in his well-known distinction between 
competence and performance (Chomsky, 1965). Competence is a person's knowledge of the set of underlying rules of grammar that enable the generation of well-formed grammatical sentences. Performance is the actual sentences that speakers produce and that may be agrammatical or ill formed in a variety of ways. The important research enterprise would be to focus on competence which, while it may not be observable, is what is crucial about language. Performance may be hard to eliminate from research, as there is no direct empirical route to the study of competence (Chomsky emphasised the value, but also the fallibility of the researcher's grammatical intuitions). Nevertheless, the task of this form of research was to get beyond the flawed world of performance to the rather more fundamental world of competence.

A second, and closely related, implication of this is that active, practical, situated and interactional features of language are secondary. Indeed, the focus is very much on language rather than, for example, talk (something that happens between people in settings), conversation (with its interactional nature), or discourse (with its performative emphasis). Skinner's behaviourist approach was taken to have shown the futility of a more empiricist approach to language. With the benefit of hindsight, particularly hindsight illuminated by thirty years of conversation analysis, there is something a little absurd about the way Chomsky confidently and successfully framed Skinner as the arch empiricist. His Verbal Behaviour is full of imaginary examples and speculations, and all of these are tightly built using the theoretical language of behaviourism: operants, stimulus and response, rewards and punishments, mands and tacts (the specific terms for utterances with different kinds of reinforcing roles). It is very far away from an observational science of language in use.

A third implication of Chomsky's approach was that cognition was essentially modular. This went strongly against the behaviourist approach to language learning that treated it as the consequence of the sum of different stimuli and reinforcements. For Skinner 
there was no essential difference between general laws of learning and the laws that operate when learning language. Chomsky's postulation of the LAD was the basis for a vision of mental specialization grounded in neurological systems. This modular vision extended to a swathe of mental phenomena became a central part of contemporary cognitive science.

\section{Modules and Representations: Miller and Fodor}

A key paper in the establishment of the cognitive perspective in psychology was George Miller's 'The magical number seven plus or minus two' (1956). The simple thesis (that, for example, people tend to be limited in the number of discrete items they can recall) belied the challenge to behaviourist orthodoxy that emphasised plasticity rather than limitations.

Miller went on with Galanter and Pribram (1960) to develop an alternative model of action that was based on TOTE units (Test Operate Test Exit). They used hammering in a nail as a simple example. You test to see that the nail is sticking up. You operate the hammer to bang it in. You test to see if it is still sticking up and so on as many times as it takes. When you test and find the nail is flush then you exit. These simple feedback units could be combined together to generate more complex actions. The empirical success of TOTE analysis was limited, but its vision of the organization of action was important in cognitive science. In particular, it offered the basis of a modular account, with large numbers of TOTE units being yoked together to perform complex tasks.

A key figure in the development of modular accounts of cognition was the philosopher (and close colleague of Chomsky) Jerry Fodor (1983). His work provides the most thoroughgoing philosophical embrace of cognitive science and cognitivism: the programme of explaining action by way of the contents and organization of individual human minds. Rather than see mind built up through the combination of simple ideas into more 
complex (as in the classic picture at the heart of Locke's philosophy) he argues for specialized modules for different kinds of processing. These may have their basis in brain systems. For example, Fodor breaks down human 'input systems' into a series of modules. For vision, say, there might be 'mechanisms for color perception, for the analysis of shape and for the analysis of three-dimensional spatial relations. They might also include quite narrowly task-specific 'higher level' systems concerned with the visual guidance of bodily motions or the recognition of faces of conspecifics' (1983: 47).

Fodor has developed a classic cognitive science information processing approach that puts representations at the heart of mind. For him, to understand what cognitive processes do it is vital to understand how representations are manipulated. Such an approach is at the heart of cognitive science:

The central hypothesis of cognitive science is that thinking can best be understood in terms of representational structures in the mind and computational procedures that operate on those structures (Thagard, 2002)

Fodor (1975) argues that as thinking requires the manipulation of representations, then there must be a language of thought. Representations must be symbolically encoded in some way, and there must be rules for the manipulation of those symbols. And Fodor develops Chomsky's nativist approach by suggesting that humans have considerable innate knowledge that will be triggered by features of the environment.

\section{Internal critiques and developments: Connectionism and situated cognition}

The overview over the past few pages has picked out only a very few features of what is the huge and heterogeneous field of cognitive science. We have tried to give a flavour for interaction researchers for whom the main ideas in cognitive science may be less familiar. Two sorts of developments are worth noting, because of their potentially radical implications 
for cognitive science and their interest for the arguments of this book. They are connectionism and situated cognition.

Connectionism emerged within cognitive science in the 1980s. It was inspired by observations of the operation of networks of computer processors with low capacity joined together. Such networks could be 'trained' to do tasks, such as discriminate between different perceptual arrays. Information processing would be achieved through the 'interactions of large numbers of simple processing elements called units, each sending excitatory and inhibitory signals to other units' (Rumelhart, et al., 1986: 10). These were seen to mimic the organization of neurons in the brain and therefore be better simulations of how actual cognitive processes might be performed. Thus 'words, objects, simple concepts (e.g., DOG), etc. are assumed to be coded as a pattern of activation across many processing units, with each unit contributing to many different representations' (Bowers, 2002, p. 414).

Although a range of attempts have been made to reconcile connectionist approaches with mainstream cognitive approaches, there are important tensions between them (see Garson, 2002). Here are three examples. First, the emphasis on distribution of the representation of information across networks goes against the modular and hierarchical view in much cognitive science. Memory and knowledge would not be stored symbolically and locally, but would reside in the nature and connection of units. Second, connectionist approaches typically model processing as something happening in parallel across the system rather than sequentially in modules. Indeed, connectionist researchers have argued that the speed of processing of neurons means that important cognitive operations must be done in parallel because they would be impossible to complete within observed reaction times if done sequentially. Third, classic cognitive science builds on concepts from (a particular version of) folk psychology. For instance, Fodor (1988) argues that the folk psychology of desires, goals, plans and beliefs is too good to be false. It is not just a way of speaking, but also a 
representation of elements of cognitive processing. Many connectionists argue that although folk psychology is provides intelligibly for human affairs, that fact alone does not make it an accurate picture of the organization of cognitive processing.

Connectionism is very much a development within cognitive science. Connectionists accept most of the same meta-theoretical and methodological premises as other cognitive scientists. They tend to work with computer programming and experimental simulations in laboratories. However, there are critics from with the broad cognitive science tradition who have become concerned that some of the taken for granted elements of cognitive research are less a product of empirical study as an artefact of particular theoretical assumptions and methodological decisions. For example, Ulric Neisser authored the hugely influential first textbook in cognitive psychology (Neisser, 1967). Yet within 10 years he was arguing that the study of cognition had focused too much on cognition and behaviour abstract from its natural settings of use (Neisser, 1976). The rationalist emphasis of figures such as Chomsky and Fodor treated many features of cognition as wired in at birth, removing much interest in considering them in natural settings. Moreover, the formulation of many cognitive science problems in programming terms (of either a modular or connection nature) treated their solution as something to be achieved, at least in the first instance, in the abstract.

Critiques of traditional cognitive work evolved into a broad programme variously described as ecological cognition, everyday cognition or distributed cognition (not to be confused with social cognition, that has largely focused on the explanation of social processes through the properties of individual cognition - see Fiske \& Taylor, 1991). Researchers in this tradition have often been influenced by Russian psychologists such as Lev Vygotsky. Their general argument is that cognition is not well understood as a product of isolated individual maturation but that features of peoples' cognitive competence are formed through interaction in situations where culture, language, and features of social settings 
themselves provide the scaffolding of individual thought (see papers in Rogoff \& Lave, 1984). The individual is apprenticed into sophisticated forms of problem solving rather than developing into them naturally. For example, Jean Lave's (1988) studies of everyday mathematical abilities showed that women were able to make subtle proportional calculations about special offers on packets of supermarket food that they could not work out when presented in the abstract. The setting and the embodiment of mathematical concepts in familiar practices provided the scaffolding for sophisticated computation.

One feature of this tradition of research is that it breaks down the customary boundary in cognitive science between mental operations and features of the environment. For example, Ed Hutchins' argues that a largely conventional cognitive science perspective can be applied to whole systems rather than just the human agents with them. He suggests this is compatible with the broad project of cognitive science:

Cognitive science... concerns itself with the nature of knowledge structures and the processes that operate on them. The properties of these representations inside the system and the processes that operate on representations are assumed to cause or explain the observed performance of the cognitive system as a whole (1995: 266). Although this approach has traditionally been concerned with individual agents, Hutchins' suggests that the unit of analysis can be extended with very little modification to cover a larger socio-technical system; this is a unit of distributed cognition (Hutchins \& Klausen, 1996).

Hutchins applied this perspective to the cockpit of a commercial airliner and particularly the issue of how pilots land planes at a speed appropriate for the weight of the plane and the configuration of wing flaps. He makes a range of observations about the cognitive properties of this system for representing and 'remembering' speed through dials and displays, and specific configurations and additions to the dials. 
Both connectionism and the various strands of work on everyday or shared or distributed cognition raise profound questions for more conventional cognitive approaches. They offer challenges and suggest extensions. However, for the most part researchers within these traditions have accepted cognitivism as the primary form of explanation in psychology. That is, to understand actions we need to make reference to some kinds of internal representations (whether distributed or hierarchical and localised, whether largely innate or built through the internalisation of cultural categories and norms). Cognition is not just the substrate or accompaniment to action, but the most immediate thing that explains action.

One of the characteristics of the contributions to this collection is that they are not working with the assumption that the explanation of action requires an understanding of cognitive states or processes of some kind. Mostly they argue for analysis of interaction that is sufficient in its own terms. However, such an analysis has potential implications for the study of, and conception of, cognition; and these are a central focus for this book.

\section{Interactional research and cognition}

For the most part conversation analytic research in particular, and interaction research in general, has developed in the context of sociology and communication departments where the key issues are to do with social structure, influence, order and so on (for overviews see Hutchby \& Wooffitt, 1998; ten Have, 1999). Conversely questions of psychology have rarely been explicitly addressed, and even more rarely have the questions that are fundamental to the discipline of cognitive psychology and the broader field of cognitive science been considered. That is not to say that the connections are not there to be made - just that there has been no need to make them. However, this has resulted in a situation where conversation 
analytic work has developed with varied and often inexplicit assumptions about the nature and role of cognition. And the converse is broadly true of cognitive science; it has developed with a model of interaction that is largely stipulative or intuitive rather based on detailed empirical work.

Elsewhere there is a tradition of 'discourse processes' that has a direct focus on psychological issues, but this has tended to use traditional cognitive science methods such as experimental studies with vignettes and has paid less attention to natural interaction (for a review, see Graesser, et al., 1997). We will discuss some of this work below. Discursive psychology is the perspective that has addressed cognition in the context of interaction most systematically in a psychological context (e.g. Edwards, 1997; Edwards \& Potter, 1992, 1993; Potter \& Edwards, 2001). We will overview these traditions in turn, starting with conversation analysis. First, however, we will highlight some of the general features that are likely to be at issue in interaction research of this kind and cognitive science.

Seven points of potential contrast between cognitive science and interaction studies

As we have noted above, cognitive science is a broad and heterogeneous field encompassing different disciplines and styles of research. Any generalization is likely to come up against a range of exceptions. Nevertheless, it is useful to highlight some differences between the style of research that makes up the core of cognitive science and interaction research of the types discussed here. We will take themes from the cognitive work we have just surveyed to make the point most clearly.

(a) Abstraction. Cognitive science, as we have seen, has drawn heavily on an abstract notion of information. The attempt was to develop an approach to information that was independent of content and could allow processing through on/off switches in their electronic or 
neurological form. As we noted above, this abstraction has been a fundamental feature of the development of cognitive science. In many ways it has been a strength. However, ethnomethodology and conversation analysis have both worked against abstraction of this kind. Garfinkel has stressed the need to understand action in terms of all the specific, local and idiosyncratic details of settings and procedures (Garfinkel, 2002). Sacks has stressed that no feature of conversation can be excluded a priori from relevance to interaction. Lexical selection is finely and relevantly tuned to requirements of interaction; and elements of talk such as laughter particles, or even sniffs, may be coordinated and have interactional significance (Sacks, 1992).

(b) Competence and Performance. Cognitive science has overwhelmingly adopted some form of this distinction and seen the explication of competence as a central research goal. This has often been combined with a view of performance as chaotic, ad hoc, and intractable, a product of multiple uncontrolled variables. In contrast, both CA and DP have avoided this dichotomy. This is seen, most profoundly, in the preference for dealing with naturally occurring interaction captured in audio and video, and transcribed in a way that captures details of delivery. This is not simply a movement from studying competence to studying performance. On the one hand, as Chomsky noted, researching competence almost invariably involves some kind of study of performance. On the other, CA and DP analyses are often focused on the organization of performance.

The subtlety of the move here can be highlighted by considering the different way rules are understood. The rules of Chomsky's transformational grammar are intended to produce all and only well formed sentences in a language (1957). In contrast, the rules of Sacks et al., (1974) classic work on conversation are intended to explicate the organization of speaker transition in talk. Three things are worth noting about rules in this CA work. First, 
the rules do not only account for smooth speaker transitions, they also account for various kinds of trouble (such as overlap and delay). These are characteristic of the sorts of (apparent) conversational disorder that encouraged cognitive scientists to move away from tackling such material. Second, note that these phenomena are largely invisible to cognitive science work that has used standard orthographic representations of talk. Third, the generation of these rules from performance data is strongly focused on what cognitive scientists would call their 'psychological reality', which is our third point of contrast.

(c) Psychological reality. Much work in cognitive science has been devoted to generating a system that could produce output that is equivalent to, or similar to, that of competent individuals. The task of showing that this system has a cognitive reality in terms of inner psychological representations and processes is a distinct one, as is the further task of considering what kind of brain organization of neurones and axons could sustain that task. Psychological reality is thus important, interesting, but not necessarily the start point for much work in cognitive science. Again, conversation analysis and discursive psychology do not make the same basic assumptions about output, competence and cognition. Nevertheless there is a strong emphasis on what cognitive researchers would gloss as psychological reality as they start with the perspective of speakers. Using the classic linguistic distinction of Kenneth Pike (1954), they are emic rather than etic perspectives. Thus, the rules for turn taking do not just generate orderly speaker transition in a mechanical manner; rather their normative status means that departures can be highly inferential. Speakers can be shown to orient to these rules as they interact. This is a special kind of psychological reality - not one defined by in-the-head mental processes, but by the participants orienting practically in the course of ongoing interaction to the relevant features of the interaction. What this means in practice is illustrated in a number of the chapters below. 
(d) Ecological naturalism. We have already noted that from within cognitive science researchers such as Neisser and Hutchins have argued for a greater degree of ecological naturalism in research. Nevertheless, only a tiny proportion of such research currently studies cognitive processes in natural settings. It is notable that cognitive sciences have developed only the most primitive representational practices for capturing and managing natural interaction in the way that conversation analysts have.

This can be shown in a number of ways. However, for illustration take the following typical example from the methods section of a research article:

The experimenter began by drawing their attention to the bags of toys and saying, "These toys are special. Do you know why they are special? These toys are special because each one has a different little thing inside." The experimenter then opened one of the toys and said, "See this toy? Look, it has a sheep inside." Gesturing to all of the other toys she said, "Each one of these toys has a different little thing inside. That's what makes them special. Each one has something different inside." (Birch \& Bloom, 2003: 282).

This is an idealization of the interaction in a number of ways. It does not include interactional details about, for example, the coordination of the experimenter's talk with contributions from the child or their displays of recipiency. Do they display attention? Do they ask questions? It renders the talk into well-formed sentences with conventional orthographic punctuation. It is not possible to recover information about emphasis, intonation, delays and repairs and so on. The interaction is, in effect, cleaned up and abstracted. Indeed, it is not clear if this is what actually happened in any case or what should have happened. From within the logic of cognitive science this is a quality of the paper. However, interaction researchers are likely to be interested in many features of what is going 
on that are simply obscured in such a representational practice. The issue here is the implication missing these features has for the way cognition is understood.

Even work such as that of Neisser and Hutchins that has a more ecological focus has been based on cognitive presuppositions, and has often been done without the degree of attention to interactional detail that we will see treated as essential in the studies below.

(e) Experimental manipulation. Cognitive science has typically been developed through experimental work using some kind of hypothetico-deductive approach to test models couched in terms of variables and abstract processes. CA and DP have overwhelmingly been developed through inductive studies of natural interaction. The cumulative success of conversation analysis has shown the value of an analytic strategy that has not found mainstream favour in psychology. The logic of these research strategies is entirely different on a number of levels. However, the contrast is slightly more complex than this bald difference suggests. Although CA studies are typically attempting to explicate the workings of a particular phenomenon in a corpus of conversational data, there is considerable attention paid to deviant and counter cases. The process of analysis involves its own finely developed form of hypothesis testing. In particular, the analysis focuses on evidence that participants are actually orienting to the claimed phenomenon - CA's own form of psychological reality is wired into its method.

(f) Representation. Arguably the notion of representation is at the very heart of modern cognitive science. CA and DP both also emphasise the importance of representation (Potter, 1996; Schegloff, 1972). However, the cognitive and interactional notions of representations are crucially different. In cognitive science representations are mental entities, perhaps represented symbolically or in the form of some kind of program. In CA and DP, in contrast, 
the focus is on actual descriptions in actual talk or actual texts, and the involvement of those descriptions in actions. For example, how are particular lexical items selected from an indefinite range of possibility to support a particular action (an invitation, say, or a criticism)? How are descriptions constructed to be adequate or literal, and how can such constructions can be unpicked or undermined in interaction (Goodwin \& Goodwin, 1997)? This practical work on representations as interactional objects, involved in practices, has a range of potential implications for cognitive science notions ideas of representations as a mental currency, not least because the nature of cognitive representations is often methodologically dependent on discursive representations in the form of vignettes or answers to researchers' questions.

(g) Modularity. A central aspect of much (non-connectionist) cognitive science is its emphasis on the modular basis of cognitive processes. A range of different modules of different degrees of complexity and proposed psychological reality has been proposed. CA and DP have a very different decompositional logic. Their focus is on turns of talk and actions accomplished in talk. Although they may identify distinct elements of turns and actions, they are not attempting to decompose interaction processes into mental modules within individual cognitive systems.

These points of contrast are intended to highlight some initial differences between the two broad approaches. For the most part interaction research has not addressed issues of cognition directly - and that is what makes this collection so significant. However, there are some important exceptions to this. In the next section of this chapter we will briefly review some of these exceptions. 


\section{Conversation analysis, ethnomethodology and cognition}

We will divide earlier interaction work into conversation analysis, ethnomethodology and discursive psychology. This is a slightly arbitrary division, and risks exaggerating differences, but it is designed to make the work accessible particularly to those unfamiliar with it. We will start with the foundational work of Harvey Sacks.

\section{Sacks, talk and cognition}

Sacks's working career through the 60 s to his untimely death in the mid 70 s parallels an important part of the development and huge expansion of cognitive science. And his work (mostly captured in transcribed and edited records of his lectures from 1964-1972, now published as Sacks, 1992) at times exhibits some of the abstract formalism of cognitive science as well as some of its language. Nevertheless, the approach to language is fundamentally different. He did not start with the John Locke picture of language as a set of signs for transporting thoughts from one mind to another. Instead, he focused on the practicality of talking. In particular, he considered the fundamental issue of how language can be something learnable and understandable. This led very early on to a caution against researchers using intuitions about cognition to constrain analysis. The very first published lecture (delivered in the Spring of 1964) ends:

When people start to analyze social phenomena, if it looks like things occur with the sort of immediacy we find in some of these exchanges, then, if you have to make an elaborate analysis of it - that is to say, show that they did something as involved as some of the things I have proposed - then you figure that they couldn't have thought that fast. I want to suggest that you have to forget that completely. Don't worry about how fast they're thinking. First of all, don't worry about whether they're 'thinking.' 
Just try to come to terms with how it is that the thing comes off. Because you'll find that they can do these things. Just take any other area of natural science and see, for example, how fast molecules do things. And they don't have very good brains. So just let the materials fall as they may. Look to see how it is that persons go about producing what they do produce (Sacks, 1992, vol. I: 11).

Conversation analysis has largely followed through this injunction in its practice, and this has had the effect of disengaging it from cognitivist thinking. Instead of attempting to work out what entities and processes may 'underlie' talk as a prerequisite for analysis, the conversation analytic programme has developed through considering the organization of actual talk. Its development within sociology meant that it could flourish without attending to cognition, nor receive the attention of cognitive scientists.

Part of the logic of this disengagement for Sacks is his positive focus on what is visible/hearable in interaction. He started from the point of view of conversationalists making sense of one another via what is said (in all its rich detail of intonation, stress, timing and so on). From this point of view cognition - mind, thoughts, intentions and so on - are relevant to, and involved in, interaction in terms of their current hearability in the interaction itself. Sacks quoted approvingly Freud's observation that 'the problem is not how is it that people come to think that others know their thoughts, but how is it that people come to think so deeply that others don't know their thoughts (Sacks, 1992, vol. I: 114)?

As an example, he considers a group therapy session where three boys jointly produce a single utterance.

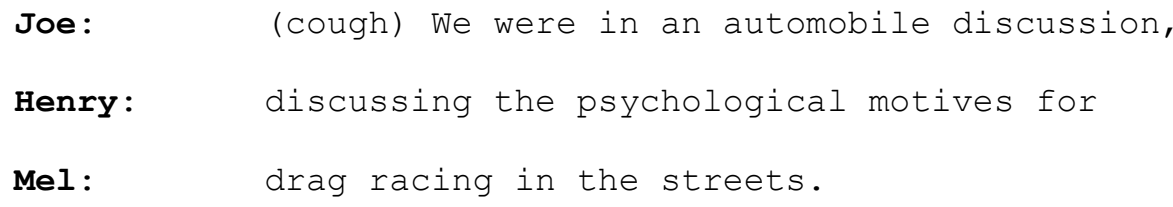


Sacks tracks this material in a number of analytic directions. One of his observations is about the way this collaborative utterance displays a particular shared understanding. It is a powerful method of for these boys to show that they concur on the topic of the talk; more powerful, he suggests, than one of the boys claiming that the topic is one thing, and the others agreeing with him. As Sacks puts it, the way they fit their talk together allows the hearer to see 'that they 'know what's on each other's minds,' (1992, vol. I: 147, emphasis added). We will return to this basic topic when discussing Schegloff's work and work in discursive psychology.

Sacks developed the issue of shared understanding in a number of ways. It is not surprising, given his sociological background, that this was such a major topic for him. Another phenomenon he focused on in relation to this topic was second stories. He noted that a regular feature of the organization of talk is that when one person tells a story of some kind the recipient of that story will tell his or her own story, a second story. This second story displays an equivalent experience. Its important feature is that the speaker does not claim they have the same experience; they show they have that experience through the telling. Again we see Sacks approaching the issue of shared experience from the point of view of the speaker and listener, and considering the question of shared experience as a practical question to be solved interactionally- in this case the answer being to provide a second story.

One of Sacks's basic ideas is that talk is recipient-designed in all kinds of nonaccidental ways. It is a medium for doing interaction, and designed in its rich detail to work in that way. He illustrates this in a manner particularly pertinent to our discussion in a consideration of the writing of Virginia Woolf. He speculates about how her writing contributes to a sense of the exploration of inner states. He notes, for example, that descriptions such as 'Mr Jones came into the room' are informative and communicative for a 
reader. However, when Woolf uses a description such as 'he walked into the room' the lack of this kind of recipient-design generates a sense of someone living in their inner world:

The idea then is that things like non-complete, non-objective, non- nominalized references do perhaps reproduce in some way, how a person having feelings that they're not in the first instance having by reference to their communicatability, has them (Sacks, 1992, vol. II: 405).

Again, we see how Sacks starts with the interactional and communicative role of language. He highlights the special literary work that Woolf engages in to give a sense of an inner life in the face of the pervasive emphasis on interaction and recipiency.

Sacks built many of the foundational ideas in modern conversation analysis in the lecture courses available as published volumes. These ideas were refined and developed in larger scale empirical studies by colleagues such as Gail Jefferson and Emanuel Schegloff.

\section{Schegloff and Socially Shared Cognition}

Schegloff (1991) has explicitly addressed the implications of conversation analysis for the way the notion of shared knowledge is understood in the context of a collection of papers on 'socially shared cognition' (Resnick, et al., 1991). He comes at the issue of shared knowledge starting with Garfinkel's (1967) ethnomethodological discussion of that topic.

This raised problems for the (still common) cognitive science picture of shared knowledge as equivalent to two computer memories having the same contents:

When even the sense of ordinary words and very simple sentences could be shown not to engender identical explications when presented to different persons, when those explications themselves had to be reconciled to provide them a "sense of equivalence," and when those reconciliations in turn required such reconciliation, the notion of "common culture" or "shared knowledge" as composed of same substantive 
components - whether norms or propositions - held by different persons became increasingly difficult to defend (Schegloff, 1991: 152).

In line with the basic ethnomethodological programme, Garfinkel developed a procedural sense of shared knowledge. That is, the issue ceased to be a cognitive question of underlying mental equivalence, but became a practical one of the way particular methods could be used to confirm (or deny) that knowledge is 'held in common'.

Again, the start point of conversation analysis is different from most cognitive science. Rather than beginning with the isolated individual and adding 'the social aspect for supplementary consideration' Schegloff argues that 'the fundamental or primordial scene of social life is that of direct interaction between members of a social species' (1991: 154). This points to the centrality of studying how agreed knowledge, understanding and so on are managed and coordinated in interaction. One of the central features about conversation highlighted by Sacks is the way that the turn taking system of talk is fundamental to coordinating understanding. Take this simple example.

A speaker makes an invitation of some kind in a turn of talk. The recipient's very next turn of talk is the place where they can accept (or reject, or put off, or query) the invitation. Moreover, and relevantly here, in so doing, that speaker shows that that they have understood that they have been invited (and what kind of invitation it is, to what kind of event, and so on). The display of understanding is crucial, because it is the idea of understanding as an interactional phenomenon that is live here. Shortcoming in this display may occasion repair in the very next turn - the displayed 'misunderstandings', 'confusions' and so on can be picked out, commented on, fixed.

In Schegloff's conception there are consequentially different structurally provided places where shared understanding (socially shared knowledge or, in a more sociological language, intersubjectivity) can be defended in conversation (Schegloff, 1992). One crucial 
place is in the turn that follows the invitation (generically, the $2^{\text {nd }}$ turn). All kinds of issues and confusions can be attended to in this place. The $3^{\text {rd }}$ turn is also crucial. If speakers can reveal their understandings in the $2^{\text {nd }}$ turn then, it can happen, 'that they can also reveal understandings that the speakers of that prior talk take to be problematic - in other words, what they take to be misunderstandings' $(1992: 1300)$. The $3^{\text {rd }}$ turn, then, is the place where the repair of such misunderstandings can be initiated. Indeed, Schegloff suggests that $3^{\text {rd }}$ turns are the last structurally provided for place for the defence of shared understanding.

Take the following example of repair in the $2^{\text {nd }}$ turn.



The first thing to note about this is that in Marcia's first turn we can already see her attending to prospective problems of understanding her utterance (she reworks what she is saying to 'helped th'mselfs', perhaps because of the possible ambiguity of 'ripped off'). This is just a more explicit element of what Sacks notes as the generic feature of talk: that it is recipient designed. Nevertheless, Marcia has not completely sorted out the understanding problem, as we can see from Tony's turn in the $2^{\text {nd }}$ position. He offers a candidate understanding of Marcia's turn, which she confirms.

Schegloff (1992) suggests that the vast majority understanding problems get sorted out through speakers designing their talk appropriately for recipients and the context, through speakers modifying and self repairing in the course of that talk, and through recipients in the $2^{\text {nd }}$ turn picking up problems that, despite this, have appeared in the talk. Nevertheless, 
problems can still arise. Through a careful analysis of a large corpus of examples Schegloff shows how repair can work in the third turn. Here is a simple example.

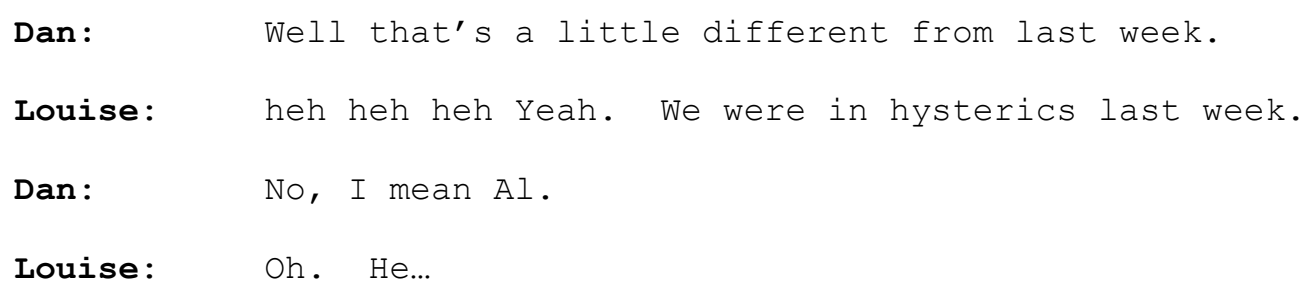

(Schegloff, 1992: 1203)

Note the way in this group therapy data Dan, the therapists, repairs the understanding of what he has said that was offered by Louise. Schegloff highlights the sorts of dangers - for relationships, for individuals - that can arise from letting failures of understanding slip past: When a source of misunderstanding escapes the multiple repair space, a whole institutional superstructure that is sustained through talk-in-interaction can be compromised. And since virtually anything in the talk can be such a source of misunderstanding, the potential for trouble for that institutional superstructure can be vast. It is against those systematic potentials for subversion of social order that repair after next turn is the last structurally provided defence (1992: 1337).

The broader point to note is the way common understanding is treated here as a procedural problem by Schegloff, on an analytic level, and by the participants at a practical level. There are different places for checking and modifying understanding, with different possibilities and constraints on them. These procedures are there for producing and constituting common understanding (or 'socially shared cognition', or 'intersubjectivity'). There is no way for participants to check such understanding independently of those procedures. This raises major questions for work on, for example, common knowledge that attempts to consider it as an issue best studied through the examination of individual performance.

While Sacks' and Schegloff's work has focused on the implications for understanding cognition from conversational organization, other workers within this tradition have 
developed different issues. In the work of Lucy Suchman we find a reworking of the central cognitive notion of plans.

\section{Suchman and Situated Actions}

Suchman opens her influential work on plans by contrasting two pictures of how navigation takes place taken from anthropology. In one picture (from studies of European navigation) the navigators uses universal principals to develop a plan that is then drawn on at each stage of the voyage to reach to goal. In another picture (from studies of Trukese navigators of the Pacific) the navigators start with an objective and head off toward it using a wide range of information about wind, tide, clouds and so on in an ad hoc manner. Suchman goes on to make the suggestion that studies of European navigation have not looked at it carefully enough, for if they would they would have found that it is much closer to the Trukese than had been imagined. Indeed, she suggests that all planned actions are more or less like the actions of the Trukese. As she put it:

Planned, purposeful actions are inevitably situated actions. By situated actions I mean simply actions taken in the context of particular, concrete circumstances. In this sense, one could argue that we all act like the Trukese, however much some of us may talk like Europeans. We must act like the Trukese because the circumstances of our actions are never fully anticipated and are continually changing around us (Suchman, 1987: ix).

She suggests that plans can only be a weak resource for activities. Indeed, their apparent central role in action may be as much a consequence of the emphasis on rationality in Western cultures than their actual constraining role.

Suchman develops this argument on the basis of general ethnomethodological thinking. Ethnomethodology has criticized conventional theories of action for 
underestimating the extent to which actions are dependent on features of local and idiosyncratic settings and ad hoc procedures (see Garfinkel, 1967 in particular). For a plan to operate in practice it needs to have specified connections to all of the available details of settings and the various contingencies within them. The risk is that a plan that can guide activity through a sequence of actions will need to become huge, perhaps impossibly huge, as it attempts the impossible task of encoding all those details and contingencies in symbols.

Suchman develops a subtly, but importantly different view, which has plans as resources for projecting and reconstructing courses of action in terms of prior intentions. Crucially the consequence of this view is that 'the prescriptive significance of intentions for situated actions is inherently vague' (Suchman, 1987: 27; see also, Suchman 1988, 2000). This vagueness is not a flaw when compared with full specification; rather the vagueness is precisely what makes plans useful for their projective and reconstructive tasks - they can be applied to an indefinite number of situations in deft and locally specific ways.

These theoretical ideas are illustrated and extended through a study of people operating photocopiers. This beautifully shows up the highly complex local and ad hoc interpretations that users make of the sequences of instructions that are intended to guide them through to the completion of tasks such as producing a two-sided bound document. Suchman recorded dialogue between users, the various actions they performed on the machines (selecting options from lists, pressing buttons, and so on), the information presented by the machine (such as numbers on displays), and, finally, the 'official' rationale for the information based on the designer's specification of the users goals.

The analysis shows up the continual reconstruction of what is going on by the users. The point of the analysis is to highlight the tension between a planful model of action embodied in the machines menu system and the local practices of users, seen from their dialogue as they jointly attempt to achieve tasks. For example, participant F selects the 
change option on the display, adjusting what is displayed from 2 to 0 . The dialogue goes like this:

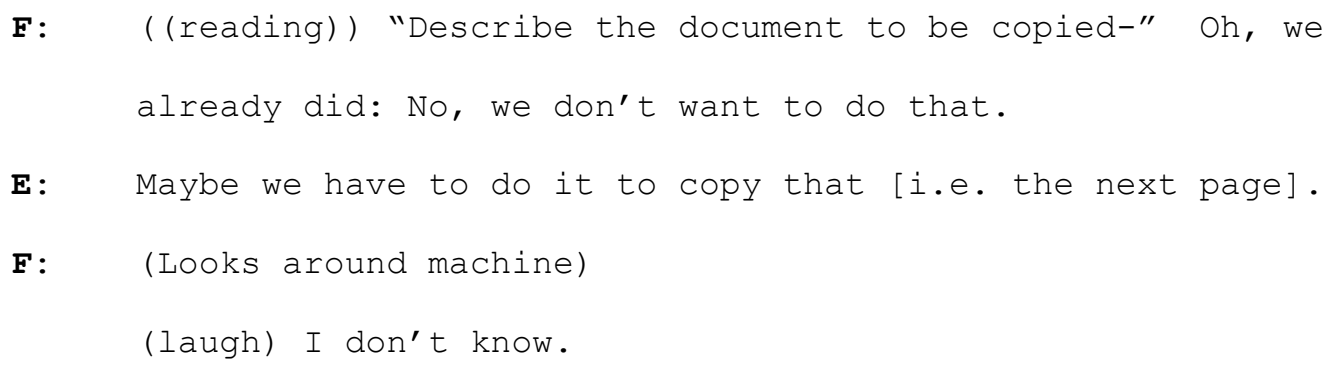

(Suchman, 1987: 151)

Suchman uses this prosaic and familiar interaction around the photocopier to highlight the basic tension between the orderly plans and outcomes that are specified in the manual, and provide the rationale for the menu system that the operators work with, and the more messy, trial and error, considerations that appear in the talk. The operators seem to navigate the controls of the photocopier like the Trukese across the Pacific - they (often) get there in the end, producing their bound and double-sided documents, but their actions on the way are ad hoc. They use the menus, but they provide local interpretations of their sense. They refer to a range of background considerations and reconstruct the orderliness of what they do as they go along, often in terms of goals and plans.

The implications of Suchman's work, along with a range of similar studies, comes from the questions it raises for the assumptions that action is based on plans. Insofar as cognitive scientists have assumed that human actions works in this kind of planful way, and attempt to model the psychological requirements for such planful behaviour, the models may be flawed by the failed assumptions. In particular, it raises problems for approaches such as Fodor's that posit a language of thought in which plans, etc. are developed. At its strongest it suggests that the whole enterprise of cognitive science may be limited by its failure to provide an adequate account of human action in its natural habitat. 


\section{Discursive Psychology and Cognition}

Unlike conversation analysis and ethnomethodology, discursive psychology has developed largely within (social) psychology and has addressed psychological issues from the start. The general theoretical and analytic framework shares many features with conversation analysis and ethnomethodology. For general overviews see Edwards (1997), Edwards \& Potter (1992a, 1993, 2001, this volume), Potter \& Edwards (2001). What makes it discursive psychology is that psychological topics are considered through the way talk and texts are used in action. Psychology is here a topic in people's talk, and a resource for that talk. This involves studying the way psychology is formulated (described, named, invoked or more indirectly oriented to) in interaction, as well as studying psychological categories and notions (such as mentalistic terms and metaphors) as tools for performing actions.

One of the features of DP has been its reformulation of a range of central topics in cognitive science in discursive terms. For example, studies have focused on the notions of memory (Goodwin, 1987; Edwards \& Potter, 1992a, b; see also Lynch \& Bogen, 1996, this volume; Wooffitt, 1991), attitudes (Potter, 1998a; Puchta \& Potter, 2002; Wiggins \& Potter, 2003; te Molder, 1999); categories and identity (Edwards, 1991, 1997; Lamerichs \& te Molder, 2003), emotion (Edwards, 1997, 1999a; Locke \& Edwards, 2003) and scripts (Edwards, 1994, 1997). To this list can be added some researchers with a more anthropological and interactional focus. Charles and Marjorie Goodwin have researched seeing (Goodwin, 1995, 1997, 2000a, b, c; Goodwin \& Goodwin, 1996, 1997). They have considered the way in which seeing is practically accomplished in the work of air traffic control, geochemistry and oceanography. For example, the category jet black has a technical sense in particular chemical processes. Diverse and locally managed practices are used to establish that a particular filament can be counted as jet black, and new members have to be 
apprenticed to be able to see this colour (Goodwin, 1997). Let us consider examples of DP work focusing on the topics of 'script formulations' and 'shared knowledge'.

\section{Script formulations}

Derek Edwards's $(1994,1995,1997)$ work on script formulations illustrates what is distinctive about DP compared with the majority of work in cognitive science. Edwards notes the way that in cognitive science scripts have been treated as abstractions from experienced reality which instruct people what to do in familiar situations (Nelson, 1986; Schank \& Abelson, 1977). They are mental representations that help people know what to expect and do in restaurants, cinemas and other familiar settings, as well as allowing exceptional or unusual events to be identified through their deviation from the script. This way of understanding scripts exemplifies how representations are understood in cognitive science as fundamental to human conduct.

Edwards (1994) distinguishes three possible references of the term script. They are:

\begin{tabular}{ll}
\hline Script-W & $\begin{array}{l}\text { Refers to ordered and orderly } \\
\text { features of the world itself. }\end{array}$ \\
\hline Script-PC & $\begin{array}{l}\text { Refers to features of an } \\
\text { individual's perception and } \\
\text { cognition. }\end{array}$ \\
\hline & $\begin{array}{l}\text { Refers to the way events are } \\
\text { described as orderly, } \\
\text { or to departures from the } \\
\text { standard order. }\end{array}$ \\
\hline
\end{tabular}

Take the classic example of a restaurant. Script-W would be the sequence of events that happen when going into a restaurant. Script-PC would be the set of propositional representations of actions in sequence tied to the restaurant setting, derived from perception of many restaurants. Script-D would be a description of what went on in the restaurant as orderly, or perhaps a description that showed how what went on departed from what was expected.

Classic script theory typically has the order of development of these scripts as: 


$$
\text { Script }-W \rightarrow \text { Script-PC } \rightarrow \text { Script-D }
$$

The objective nature and order of events $(S c r i p t-W)$ is perceptually apprehended by the individual. This perceptual information is then the basis for building up cognitive scripts (Script-PC). These scripts, in turn, provide the semantics for people talking about, describing and recalling routine places and events (Script-D). In contrast, DP proposes that this order can be inverted. Initially this is a methodological by-product of starting with a focus on discourse. However, Edwards notes that once the focus is on Script-D formulations it becomes hard to see them as a mere by-product of perceptually refined mental scripts derived from regular experiences.

Edwards shows that script formulations are analysable as interactionally occasioned phenomena. That is, they are not produced haphazardly as conversational non-sequiturs, rather they construct events in particular ways as parts of particular actions at particular moments in interaction. In particular, they presenting actions as orderly and following from standard routines (as anyone would follow) or as deflected from such routines by idiosyncratic personal dispositions. DP and cognitive science agree in seeing scripting as central in human affairs, but DP starts with the practical role of Script-Ds in actions, and providing accountability to those actions. Their place is more central than in cognitive science where they have been treated as a reflection of perceptually derived cognitive scriptPCs.

An example can illustrate the role of scripts in actions and accountability, and some of the issues it raises. This extract comes from a phone call between two elderly Californian women and describes some features of a restaurant that one of the women went to. As such is provides an empirical example to consider the nature of scripts against. 


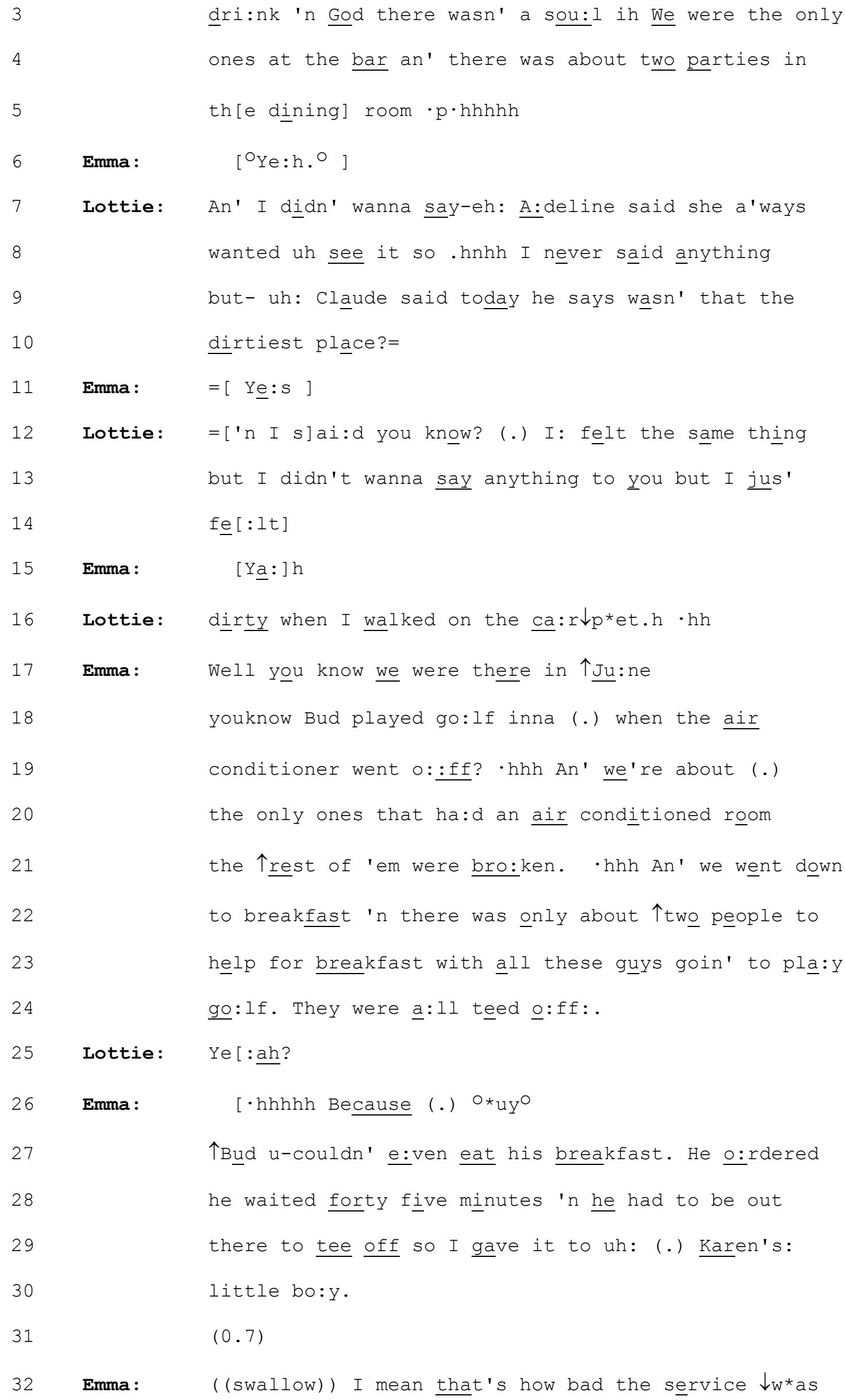

Lottie: $\quad Y e[: \underline{a h}$ ?

Emma: $\left[\cdot\right.$ hhhhh Because $(.) \circ * u y^{\circ}$ 个Bud u-couldn' e:ven eat his breakfast. He o:rdered he waited forty five minutes ' $\mathrm{n}$ he had to be out there to tee off so I gave it to uh: (.) Karen's: little bo:y. $(0.7)$

Emma :

( (swallow)) I mean that's how bad the service $\downarrow_{W}$ *as 
.hh (.) OIt's gone to pot.

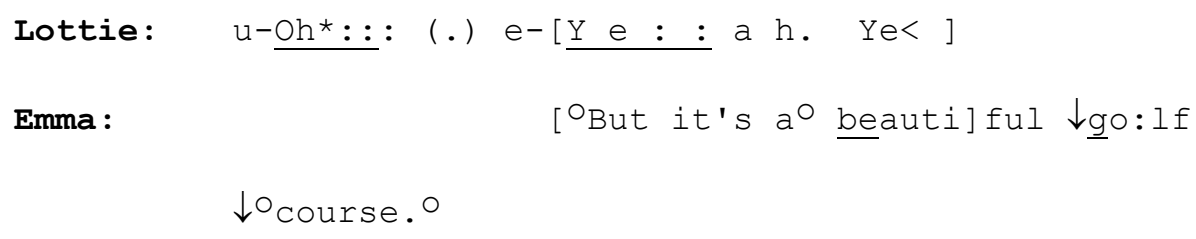

(NB:IV:10:R:35 - from Edwards, 1997: 147-8)

We do not have any trouble recognizing this string of negative assessments of the restaurant as a complaint. On the basis of cognitive science we would expect the complainable matters to be identified by reference to scripts of what should and should not go on at restaurants. However, when we start to consider this practically it becomes difficult to sort out what is included in the 'restaurant script' (script-pc) and what is not. While this script might well pick out Bud not getting his food as a problem (line 27), would it pick the insufficiency of people at the bar (lines 3-4) or the sticky carpet (line 16), or even the need to get on the golf course (lines 27-29)? These are produced in the description (script- $d$ ) as noticeable failures of what is to be expected. Yet if all considerations such as these were to be included as parts of the standard restaurant script it would become enormously cumbersome.

The DP approach is not to consider how such scripted descriptions (script- $d$ ) could be a product of noticeable departures from mentally represented scripts (script-pc), but to consider the way they are constructed from an indefinite range of possibilities to bring off the act of complaining. The script formulation (script-d) warrants the complaint. Edwards notes that the empirical details are finely tuned to the performance of complaining, and potentially problematic as features of a cognitive script (script-pc). For example, some of the elements here that are built as negative, might elsewhere be built as 'as characteristics of a desirably folksy, laid-back, informal sort of restaurant that contrasts favourably with places that are antiseptic, regimented and characterless' (1997: 148-149). This suggests that having decontextualised, mental templates of good restaurants and how they operate might not be the most useful prerequisite for dealing with and talking about restaurants where it might be more 
useful to have 'descriptive details as inventively produced and made relevant as part of the production of situated accounts' (1997: 149).

DP shifts the analytic focus from cognition to description, from script-pc to scripts-d. In part this reflects a different but complementary focus of study. However, the tension is potentially sharper. Edwards observes that in practice cognitive psychological work on scripts does not, and cannot, access scripts-pc directly, but typically works from script- $d s$ to script-pcs. This is true of theoretical treatments, researchers' accounts of scripts, experimental and simulation procedures and studies of narrative completions. Thus research on script formulations and their role in situated actions is likely to be fundamental to appreciating what any possibly reformulated script theory in cognitive science is required to explain. Just as with Suchman's (1987) work on plans, the general implication is that simplified ideas about the 'language of thought' and the relation between scripts and actions are likely to be flawed. As Edwards puts it, script formulations provide:

a basis for accountability, rather than a program for generating the activity itself. We should add that they may also be invoked reflexively within action sequences as formulations of the kind of activity it is, as a criterion for what to do next, or for what has gone wrong. But each time they occur in these ways they feature as actions in their own right, in the form of situated descriptions (1997: 166).

\section{Shared knowledge}

We have already discussed Schegloff's approach to the notion of shared knowledge. Let us develop this discussion by considering both Edwards' $(1997,1998)$ work on shared knowledge and Herbert Clark's (1996) discussion of the topic. Clark's work is worth considering because he is a rare example of a cognitive psychologist who has drawn on 
interaction research. It highlights important tensions between cognitive and interactional approaches.

For Clark, when two people share knowledge, or 'common ground', this is 'the sum of their mutual, common, or joint knowledge, beliefs, and suppositions' (1996: 93). Clark asks: given that two mental spaces contain the same knowledge, how can they be coordinated through talk? For Edwards there are basic problems of this way of formulating the question of shared knowledge (Edwards, 1999b). For him it closes off two issues that are at the centre of interaction. First of all, concerns with knowledge in interaction are inseparable from concerns about description. Second, agreement is something that is established through conversational means. The first of these has been particularly emphasised in DP, the second picks up from the tradition running through Schegloff and Garfinkel of treating shared knowledge as a procedural issue that we have already discussed.

Let us illustrate these points with an example. The following is start of a call to a child protection helpline:

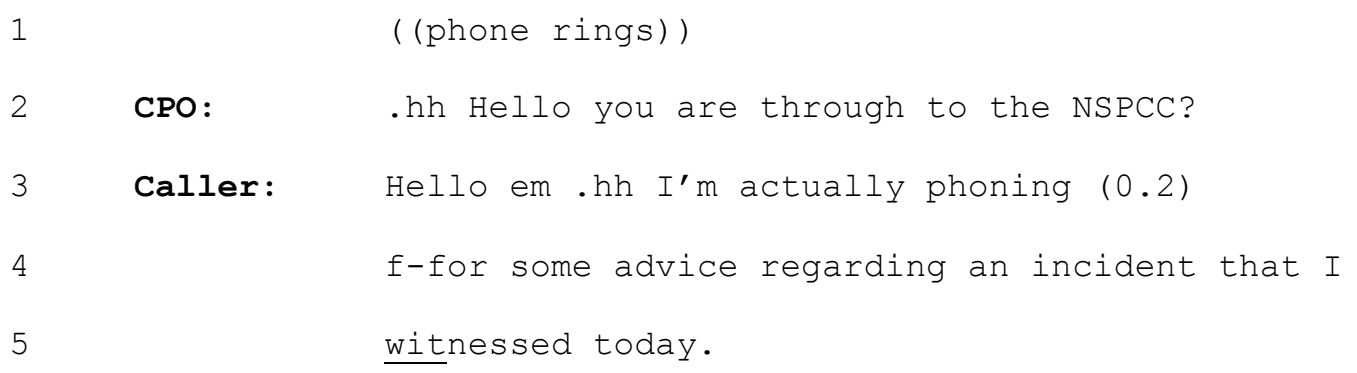

At this point the Caller has some knowledge that the Child Protection Officer does not. For Clark common knowledge will be established when both share that knowledge. However, the DP perspective highlights the role of specific descriptions and the inseparability of knowledge and description. Note that in using the term 'incident' here the caller does not evaluate, or assign responsibility. It is the most limited of characterizations. As such, it orients to the expertise of the Child Protection Officer by allowing the status of 
the incident to be established interactionally (Potter \& Hepburn, 2003; cf. Zimmerman, 1992). From a DP perspective, there is no easy way of separating the 'knowledge' or 'belief' from its linguistic construction. Moreover, for the participants the linguistic construction must be paramount - it is what they are starting with.

Edwards's second point is that 'agreement' in interaction is something accomplished actively and practically rather than being simply a consequence of the overlap of putative underlying 'knowledge' or 'belief states'. Again, this is not just a DP point, but follows from basic thinking in ethnomethodology and CA. Take our example again. After the Child Protection Officer has checked for ethical permission and described the role of the helpline, she continues with the following:

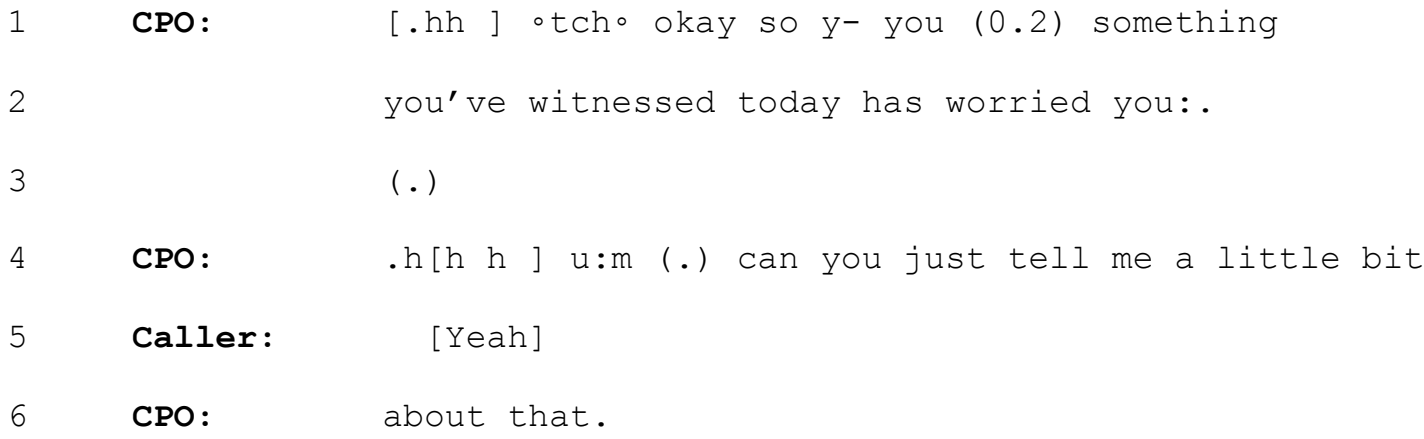

Note here the way the CPO ascribes a mental state to the Caller ('worried' - line 2) as well as describing what has worried her as 'something' (line 1). Again, for discursive psychologists the first issue is what the talk is doing in public and practical terms (again, reflecting the necessary primacy of talk for the interactants). Rather than reflecting a shared understanding of underlying mental contents, the ascription 'worried' can be an element in constructing an appropriate stance for the caller from which to be making the call. Moreover, the word 'something' (like the caller's own word 'incident' earlier in the call) allows the precise nature of the phenomenon to be established over the course of the call, supported by the CPO's skills in child protection. For DP, then, terms for mental states such as 'worried' and descriptions of events such as 'an incident' or 'something' are explicable as delicately 
interactionally designed specifics. In this case, they are moves in the business of doing orderly reporting of child abuse, occasioned by that business, rather than traces of actual mental states and perceptions.

As with the example of scripts and script formulations, the approach developed in DP is not necessarily in opposition to more traditional cognitive science notions. It presents a different focus on mental or psychological phenomena, starting with how those things are constructed, managed, and oriented to in natural interaction. Goodwin's studies of seeing, for example, start from vernacular understandings of seeing situated in interaction where seeing is important, such as the work of archaeologists (Goodwin, 2000a). Yet one of the consequences of such research is often to show up possibly unwarranted assumptions about the nature of descriptions and formulations that are embedded in the methods of cognitive science and psychology more generally (e.g. Antaki, et al., 2000; Edwards \& Potter, 1992b; Maynard, et al., 2002; Puchta \& Potter, 2002; Schegloff, 1999).

This way of approaching cognition is strikingly different from that common in cognitive science where psychological objects such as perception and memory are wellestablished technical domains, fenced in by the standard theories and methods of psychology and related sciences. Often it is not just specific claims that are at stake here, but broader approaches to empirical work through which claims could be tested, and the broader theoretical perspective in which the claim is embedded. These obstacles have made dialogue complicated - yet the potential is there. The payoff is the possibility of developing some genuinely new ways of considering questions of cognition. This is one of the goals of the current book. For the rest of this introductory chapter we will overview the contributions and set them in context. 


\section{Contributions to this book}

We have tried to set the scene for the chapters that follow with a necessarily synoptic mapping of the terrain of cognitive science and interaction research. This highlighted some of the subtle considerations about the nature of cognition that are at stake. As a broad-brush distinction between the two areas we might characterize the cognitive science question as what kind of competence is required to produce particular actions? In contrast, the interaction question can be characterized as how (if at all) does cognition figure as something in and for interaction? This raises further questions of whether the answer to the former question has implications for the latter, and vice versa. Does the competence concept in cognitive science map onto the interactional objects of interaction research? These challenging questions are not going to be answered in a simple way in what follows, but they do offer the most elaborate consideration of them that has so far been produced.

The chapters are organized into two halves. The first set address basic issues of the interface between cognition and action, and the implications of such research for method. Whereas Robert Sanders argues for the findings of cognitive science as a limit on the claims of interaction research, Jeff Coulter offers the most thoroughgoing rejection of both cognitivism as an explanatory principle and cognition as a coherent research topic. These two chapters mark out two boundary cases. Anita Pomerantz follows up the implications of treating cognition as something relevant to interaction analysis by commenting on, and refining, an analytic approach. This couples direct analysis of interaction with the use of video stimulated comments from participants who were part of the original interaction. Nora Cate Schaeffer and Douglas Maynard argue the other way, highlighting how basic features of interaction have consequences for the responses in standardized surveys. They consider cases that are typically treated as deviations from standard scripts produced by 'cognitive 
processing' and suggest that they should be understood as something interactive and collaborative. Finally in this section Robert Hopper's chapter marks a transition point. He analyses a corpus of phone calls made during the first days of President Lyndon Johnson's presidency, a data set perfectly suited to addressing the notion of strategic thinking. He asks what interactional evidence is there that the president's talk in those calls was strategically planned.

The second half of the book addresses the issue of cognition through a series of studies of how particular 'mental phenomena' figure in interaction. Paul Drew analyses 'confusion' and tries to show how analysis might identify it as a 'mental state', independently of participants' orientations to that state. John Heritage focuses largely on the particle 'oh' and its potential relation to changes of mental state. Robin Wooffitt, and Michael Lynch and David Bogen address questions to do with the mental and interactional status of memory, in both cases arguing for a non-cognitive approach. Wooffitt considers the phenomenon of flashbulb memories through a discussion of the organization of descriptions of unusual or surprising events. Lynch and Bogen discuss the status of memory in discussion of Oliver North's testimony to the Iran-Contra affair. Finally, Derek Edwards and Jonathan Potter illustrate a non-cognitive approach to claims to knowledge and description, liking and thinking.

We will spend a bit of time describing the argument of each chapter and then draw out some of the broader issues they address. We will take the contributions in turn.

\section{Sanders: Testing “Observations".}

Sanders argues that discourse researchers should pay serious attention to the findings of cognitive science. Indeed, he contrasts his own stance with what he sees as the neobehaviourism of discursive psychologists. He notes that although much of the time discourse 
researchers can safely ignore the findings of cognitive research there are times that it is important to take such findings into account. He develops this argument by considering examples from CA (Schegloff, 1996) and DP (Potter, 1998). In each case he suggests that the analysis involves a hidden attribution of motive to speakers, and that there is evidence in the material that alternative motivations might be available, or that the material might simply reflect their cognition or, as he puts it, the utterances could be 'actually expressions' of how speakers 'in fact did experience' something, and that what [they] said could have been 'dictated by [their] inner state'. The challenge for interaction researchers is to show how an analysis can be developed that does not depend on an inner, psychological notion of motive and to demonstrate the insufficiency of the idea of inner states dictating what is said (for more on these arguments see, for example, Potter, 1996; Schegloff, 1972; Wittgenstein, 1953).

Sanders considers examples from both child and adult interaction to illustrate the way in which interpretations made by researchers should be disciplined by the cognitive science findings about processing limitations. For example, he returns to an extract analysed by Schegloff (1996) and suggests that the analysis requires that the speaker is performing a particular cognitive task that involves a word search. The issue is the relation of this task to experimental work. If Schegloff is right his 'analysis makes a contribution to cognitive science for revealing the power of the cognitive resources we bring to bear in producing discourse objects; but if cognitive scientists should find that it is not cognitively possible, then Schegloff “observed" something that did not actually take place' (Sanders, this volume, p. $\mathrm{xx})$.

Sanders' chapters raises fundamental issues about the relation between cognition and interaction, and highlights just how difficult they are to answer. In the case of the Schegloff example, if there was a strong tension between his finding and that of experimental work in 
cognitive science, one place to start might be to ask questions about the 'operationalization' of the task in the experiment. Maybe the research approach itself would become the analytic focus. The service that Sanders has done is to offer specific and detailed interpretations of materials and to highlight their relationships to particular studies in cognitive science. More generally, his challenge is to see how far talk must be understood as psychological motivated and dictated by inner states. One of the features of the chapters in the second half of the book is the novel and rigorous ways they pick up and develop these issues.

\section{Coulter: Language without mind.}

While Sanders makes the case for interaction researchers taking the findings of cognitive science more seriously than they have up to now, Coulter makes a trenchant case for the incoherence of the whole cognitive science project. In a series of publications (particularly Coulter, 1979, 1983, 1990; see also Button, et al., 1995) he has drawn on linguistic philosophy (notably Ryle and Wittgenstein) and ethnomethodology to argue for a position that is anti-mentalist, anti-Cartesian, and anti-'telementational', Instead he argues, following Norman Hunter (1971), that linguistic expressions convey intelligibility without the need to supplement them by something like thinking, deliberation, disambiguation or similar operations as commonly claimed by linguistic theory.

Coulter is dismissive of the common cognitive science approach to discourse comprehension involving cognitive representations. He argues that such an approach confuses understanding discourse with interpreting it, and compounds the problem by developing empirical tests that presuppose the existence of the very thing they are supposing to be testing. He restates the linguistic philosophical critique against mentalism in a strong form that provides a way into this important and relevant body of work. 
Coulter also devotes considerable space to highlighting what he sees as a cognitivist strand in the work of conversation analysis, although much more in the work of Schegloff than Sacks. He suggests that Schegloff has drifted into a form of cognitive science that takes parties to an interaction to be performing analysis or cognitive operations such as problem solving as they interpret talk. That is, it turns talking into a talking and thinking combination. Whatever the merits of this particular critique of Schegloff, whose take on cognition we have illustrated above, Coulter has highlighted a potential ambivalence over the status of cognitive terms and cognitive states in conversation analytic work. We will see this ambivalence explored in difference ways in the papers in the second part of this book. It is clear that most of them concede more to a cognitive perspective than Coulter is willing to. The value of Coulter' chapter in this collection is that it offers the most fully non-cognitive, indeed anticognitive position, thus requiring those who wish to include a cognitive level of analysis of cognitive findings, to make the case for that inclusion.

Whereas Sanders and Coulter mark out different poles on basic issues of the status of cognition, Pomerantz and Schaeffer and Maynard are more concerned with how issues of cognition become live in analysis.

\section{Pomerantz: Using video stimulated comments.}

Up to now Pomerantz has addressed the role of cognition in interaction research in different ways. On the one hand, she has developed analyses that show how concepts that are traditionally seen as falling under the purview of cognitive science (attitudes, knowledge) can be understood as interactionally embedded (Pomerantz, 1980, 1984a,b). Her hugely influential work on assessments, for example, shows the way in which assessments can be studied as a conversational practice without starting with the speaker's attitudes (Pomerantz, 1984a). On the other, she has attempted to explicitly address the way cognition should be 
understood, and enter into, interaction analysis (Mandelbaum \& Pomerantz, 1990; Pomerantz, 1990/1991). In her chapter for this volume she addresses issues of cognition from a methodological direction, attempting to marry the two strands of her work.

Many psychological methods take a cognitivist approach to the actor. When a person is interviewed, for example, about why they did something the assumption is that people can access again the very same cognitive resources that led to the action in the first place - their opinions, say, or desires. At the least the assumption is that they can access reliable memories of the event. As we have seen above, conversation analysts in particular have been sceptical of this way of working, and have overwhelmingly opted to analyse records of actual interaction occurring in natural situations. The advantage is that it captures organizations of interaction, and features of actions and events, that are often hard to formulate, let alone remember. For example, the closing stages of telephone calls have an exceedingly regular pattern to them (see Hopper, 1992; Schegloff \& Sacks, 1973), but it is doubtful that people could precisely recall that pattern.

Pomerantz is well aware of the reasons that conversation analysts in particular have avoided interviews and questionnaires. However, she takes the position that there may be cognitive phenomena such as understanding, or aims, that are relevant to peoples' practices. She argues that there are times when reports of such phenomena are a pathway to the phenomena themselves, and that the evidential basis of such reports can be strengthened by stimulating people to comment on video showing their own interaction. Pomerantz develops her argument through a rigorous consideration of particular cases. To end with she considers some basic conversation analytic notions - such as display and orientation - and suggests that it would be valuable for analysts to go beyond the agnostic stance on cognition implied by these terms, and accept - both in principal and for some analytic practices - that it may be possible to distinguish real understandings from displays of understanding, and perceptions 
from orientations. The challenge here, then, is the suggestion that CA is already more cognitivist than is usually recognized.

5. Schaeffer and Maynard: Interaction and "cognitive processing" in survey interviews. In this chapter Schaeffer and Maynard focus on the question of how 'cognitive processing' contributes to the conduct of standardized surveys. It is similar to the Pomerantz chapter in its focus on methodology. However, it argues in the opposite direction. Whereas Pomerantz is arguing for the introduction of some cognitive notions, and some methods underpinned by cognitive thinking, into interaction analysis, Schaeffer and Maynard attempt to show that a range of phenomena in the administering of standardized surveys are more interactional than psychological. The chapter builds on a series of powerful and influential studies of survey research interaction (Maynard \& Schaeffer, 1997, 2000; Maynard et al., 2002; see also Houtkoop-Steenstra, 2000).

Schaeffer and Maynard review traditional psychological work on standardized interviews that typically treats both smooth answering and troubled answering as the consequence of the individual cognitive processing of the interviewee. However, they suggest that a close examination of sequences where there is trouble shows that the interviewee's actions are closely coordinated with the actions of the interviewer. For example, they note that silences like the one on line 250 of the following are typically treated as markers of cognitive processing by psychologists.

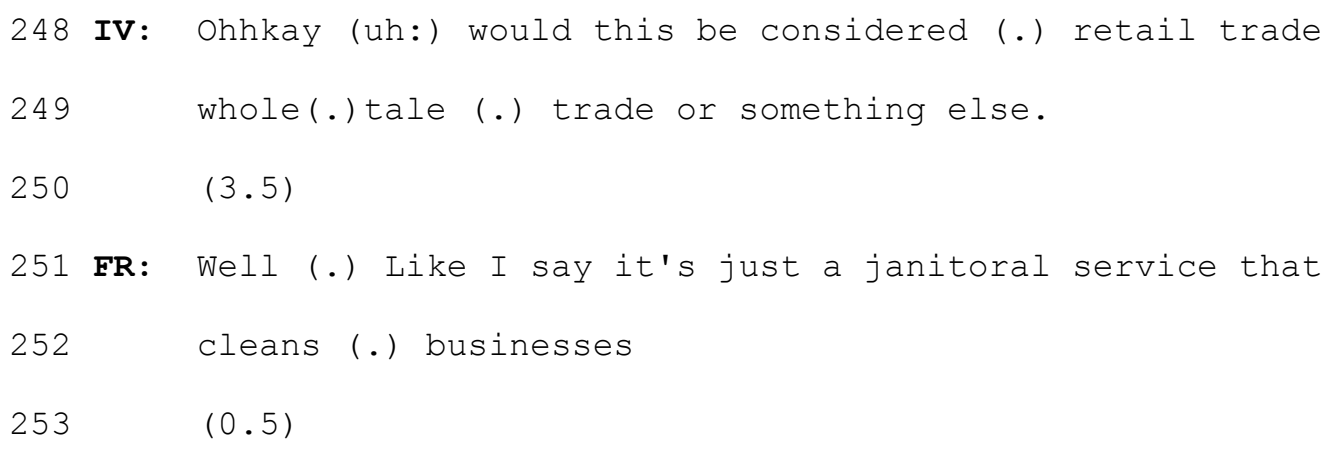




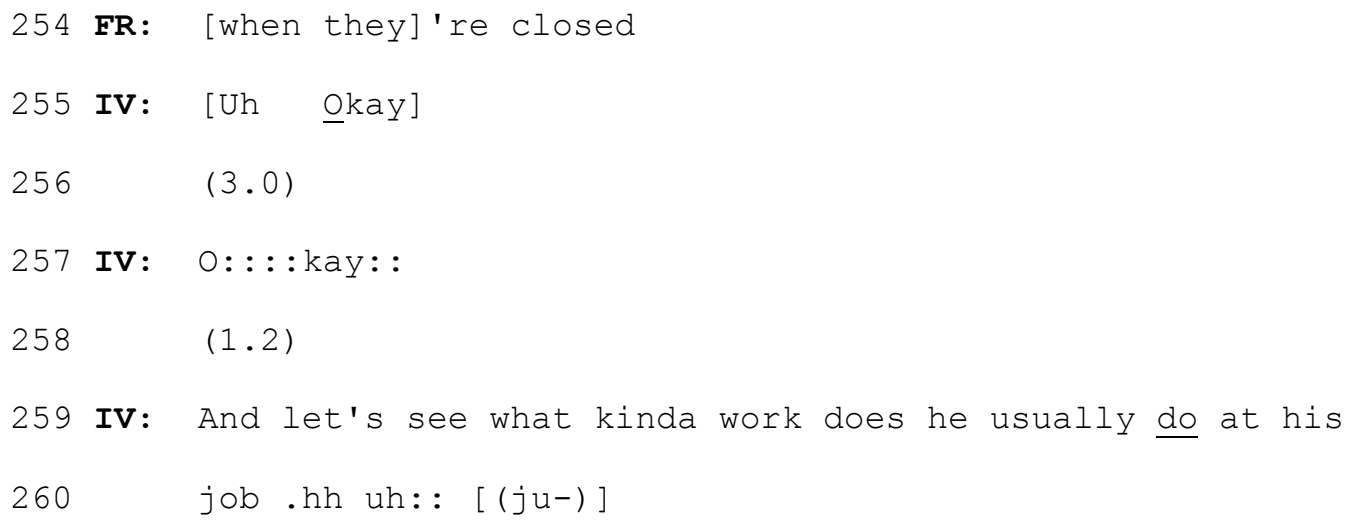

Schaeffer and Maynard, however, suggest that the delay may be a display of uncertainty. It may be an interactional resource, indicating that the answer is perhaps not an expected one in that is a repeat of earlier information (Well (.) Like I say). And the interaction proceeds with the interviewer displaying that they have constructed a codable answer from the respondent's talk. In terms of what is displayed by the interviewee, the interviewer shows that they have picked it up.

Using a series of examples Schaeffer and Maynard argue that 'in many cases the interviewer performs work that the individualistic psychological model of cognitive processing locates in the respondent' (this volume, $\mathrm{pp} .{ }^{* *}$ ). They claim an agnostic stance on the matter of individual cognitions, preferring to focus on what can be observed in the interaction, and how the actions of the interviewer contribute to what had traditionally been seen as cognitive.

\section{Hopper: A cognitive agnostic in conversation analysis.}

This chapter is one of the last pieces of work written by Robert Hopper before his death. His writing has been highly influential within conversation analysis, as has the influence of his numerous $\mathrm{PhD}$ students across the fields of sociology, communication and social psychology (see Glenn, et al., 2003). This book is dedicated to Robert Hopper - and it is appropriate 
that he has produced something both subtle on the issue of cognition and fascinating in its insight into the early days of the LBJ presidency.

Hopper's discussion of the status of cognition in conversation leads off from John Heritage's (1990/1991) important paper on the nature of strategy. Heritage tried to distinguish two kinds of strategy. On the one hand, there is strategy where the actor thinks out a goal beforehand and has a conscious, maybe surreptitious plan of how to achieve it. Hopper calls this a pre-strategy - a mentally represented strategy existing and guiding the subsequent interaction. On the other, there is strategic action that is the result of simply following particular conversational routines (which might have some internal complexity) in a non-conscious or planful manner. Hopper calls this an emergent-strategy as the strategic action emerges with the interaction. As he puts it:

no participant anticipates or plans this pattern. Rather, the speakers generate the sequence out of the normal turn-by-turn course of interaction. The pattern turns out to be a kind of found art for analysts, and to some degree for actors (this volume, pp. $* *)$.

Heritage considers this distinction (differently glossed) in terms of two phone calls that are part of a corpus used in many conversation analytic studies. In each call a personal narrative about the recent assassination of Robert Kennedy and the movement of the body is 'touched off' by the organization of the call. Heritage suggests that the two calls together provide evidence for the operation of a pre-strategy. The surprise displayed in the second call seems disingenuous following so soon after the same pattern in the first call. Hopper is more doubtful, and considers the potential workings of these two kinds of strategy in a corpus of calls made from and to President Johnson's office soon after he became president. This series of calls, often doing rather similar things (thanking supporters, accepting 
congratulations and so on) allows for a more extended examination of the interactional criteria that might be developed for identifying pre-strategies.

Hopper teases away at these calls, trying to identify what evidence would be strong enough. For example, he notes that LBJ receipted a series of compliments in calls in much the same way, but suggests that as a competent conversationalist such receipts are a standard resource, and not something that needs to be consciously planned. However, he notes that the pattern of compliment responses evolves through standard forms to something close to boasting and fishing for compliments, then back to more standard compliment receipts. $\mathrm{He}$ focuses on another feature of the calls, which is the introduction of the term 'thrift' into compliment responses. Here is an example $(\mathrm{C}$ is compliment, $\mathrm{CR}$ is compliment receipt, $\mathrm{T}$ is the 'thrift' mention):

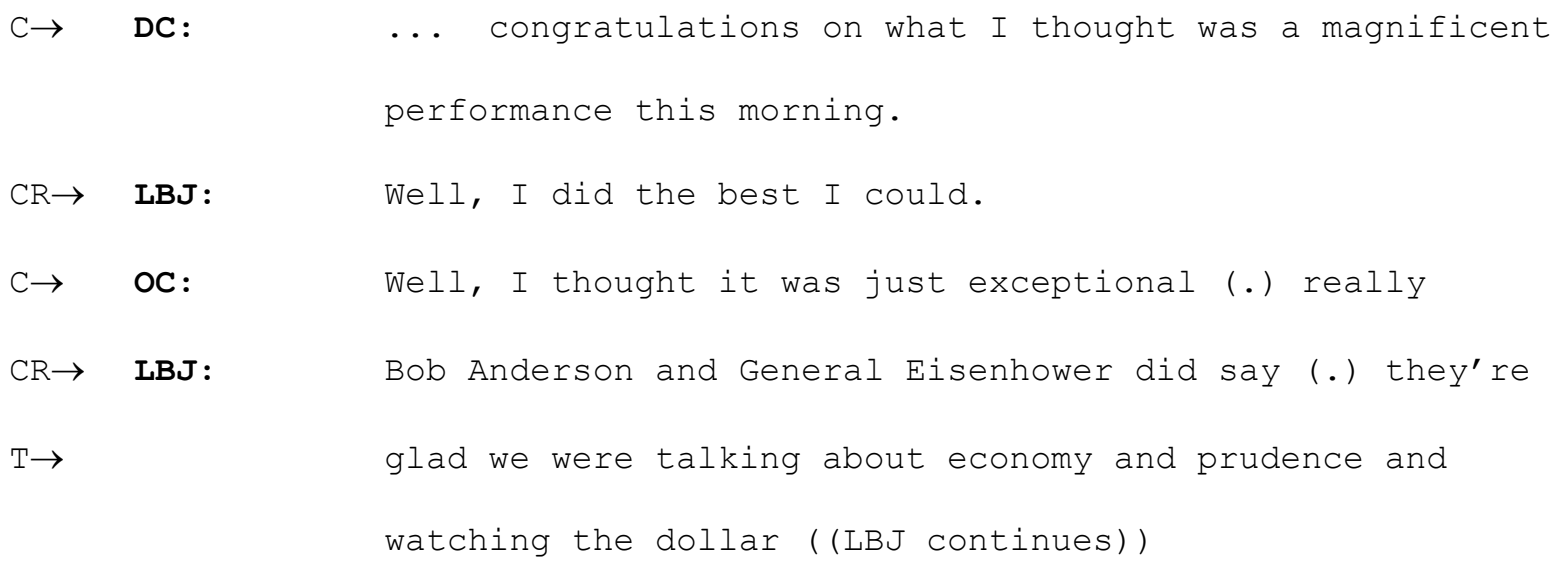

Again, Hopper explores the possibility that these mentions are pre-strategy, a way of LBJ subtly developing the cost cutting agenda that was part of his presidency while deftly doing compliment receipts. Yet even with these latter examples it is hard to show it was planned beforehand, particularly with the fluid insertion in the conversational flow. Even as a prestrategy it would be more Trukese than European! Hopper concludes cautiously that there are some cases where pre-strategies may be operating but they are both a-typical and hard to pin down. Hopper's chapter is, in many ways, the centre of the book setting up issues that are picked up in a series of studies in the second half of the book. 


\section{Drew: Is confusion a state of mind.}

Like Hopper, Drew introduces his chapter with a series of cautions against the reading of 'states of mind' off what people say. He notes that the standard conversational patterns for turning down invitations, for example, suggest a state of mind on the behalf of the speaker (wanting to accept, but constrained by circumstances). Yet such declinations 'can enable speakers to disguise their actual states of mind (what their actual intentions are, how they really feel etc.)' (this volume, pp. $\left.{ }^{* *}\right)$. Nevertheless, Drew argues that careful analysis of examples can reveal a connection between talk-in-interaction and cognition (see also, Drew, 1995).

Drew considers examples of invitation refusals where early and inexplicit signs of refusal are picked up and acted on. He suggests these are 'cognitive moments'. That is, they are moments where a speaker can, in a profound sense, read the other's mind; they can identify intentions and act on those intentions. He develops this way of thinking with the example of 'confusion'. He starts by considering examples where participants use the category 'confusion' attributionally. However, he attempts to go beyond such participants' uses.

His more ambitious aim is to identify 'confusion' as a participant's mental state that has been generated through interaction. Confusion is explored in detail with a series of examples. Drew identifies a number of features that support the use of the analytic category ‘confusion' (including repair initiations, styles of acknowledgement, and characteristics of intonation). Drew notes that this mental confusion is interactionally generated through the confounding of expectations derived from conversational norms. It is the interaction that generates the mental state rather than the other way around. Nevertheless, this confusion as a cognitive object need not be salient to participants - for example, participants do not remark 
on it. It is not being used as a resource in the interaction, to request clarification say, rather it is evidenced through its conversational symptoms. The general point is to use information about interaction and its normative organizations to be able to identify, as an analyst, a particular mental state of confusion. Drew is trying to show how cognitive psychological topics can be informed by careful analysis of conversation.

\section{Heritage: Cognition in discourse.}

Heritage's important earlier contribution to theorizing issues of cognition and interaction has been described above, and is discussed in detail in Hopper's chapter. In his chapter for the current volume Heritage starts by noting examples where descriptions of events (in a doctor's surgery, in a call to the police) are marshalled in a way that displays something about the position of the caller as 'innocent' or 'unmotivated', thereby underpinning the reasonableness or credibility of the reports. This is linked to a tradition of work that includes studies in ethnomethodology, conversation analysis and discursive psychology (Edwards, 1997; Heritage, 1984a; Pollner, 1987) and picks up themes that will be explored further in the chapters by Wooffitt, Lynch and Bogen, and Edwards and Potter.

The focus of this chapter, however, is not the relation of cognition to description, but the way cognition may be embodied in talk-in-interaction. Heritage has done a series of studies of the use of the use of the particle 'oh' in interaction to indicate a 'change of state' (Heritage, 1984b, 1998, 2002). In his chapter he teases out cognitive themes in this work. For example, he considers the way 'oh' can 'embody the experience of a recollection' and display that experience for interactionally relevant purposes, such as when receiving good or bad news, or how it can be used to show that something relevant has been remembered. In the context of questions it can show that the questioner has not expected the answer. More generally, he notes the way 'oh-receipts' are linked to the interactional-sequential logic of 
questions where the questioner proposes her or himself as uninformed on some matter and simultaneously projects the answerer as informed. The questioner's 'oh-receipt' marks the change of state and ratifies the answer as news. Where such a logic is absent (in classroom teaching, say, or news interviews) so are 'oh-receipts'. Oh-receipts, then, are closely bound up with epistemic issues of who knows and who does not.

Heritage develops this line of thinking with an exploration of relation between the use of oh-receipts and knowledge entitlement. Oh-receipts can be used to show epistemic supremacy in interaction such as the following:

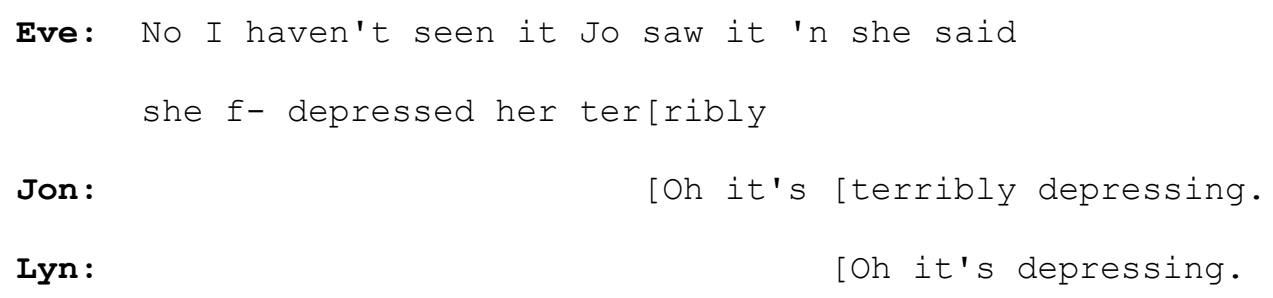

Heritage highlights the way in sequence Jon and Lyn who have seen a film agree with Eve, but oh-preface that agreement. In doing so they index the independence of their access to the film 'and in this context that, relative to Eve, they have epistemic priority: direct rather than indirect, access to the movie' (this volume, pp. **).

Analyses of cases of this kind highlight the way certain elements of talk can be used to display changes of knowledge state, or authority compared to other speakers. Heritage returns repeatedly to the fundamental question for this collection; what is the relation of 'oh' to a change in mental state? His answer is that there may be a relationship: 'it might be possible to think of $o h$ as directly tied to the experience (and the neuropsychology) of undergoing a 'change of cognitive state', such that the utterance of 'oh' indexes the arrival of such a state as its outward marker' (this volume, pp. **). Nevertheless he offers a number of cautions: cognitive states may change gradually while $o h$ utterances are point events; $o h$ may be withheld despite the cognitive event; or produced without such an event; and its production is subject to interactional and turn organizational considerations. He argues 
instead that we treat $o h$ first and foremost as a live matter of participants' social concern and accountability, rather than an abstract topic of psychological investigation.

\section{Wooffitt: From process to practice.}

Heritage, Hopper and Drew focus on particular conversational practices and consider their possible involvement with both everyday issues of practical psychological importance and their possible status vis-à-vis cognitive states and processes. They do not tackle the literature on cognitive science, or consider the way it has dealt with the relevant phenomena. In contrast, Wooffitt starts off by considering a particular phenomenon in the psychological literature, that of 'flashbulb memories'. The classic account of flashbulb memories has the receipt of dramatic or shocking news (of the death of President Kennedy, say) leading to a special kind of vivid and enduring memory encoding such that people can not only remember the event but the routine circumstances in which they received news of it. Recent work has painted a considerably more complex picture. However, Wooffitt's aim is too show that some of the features associated with flashbulb memories are features of the pragmatics of describing certain kinds of events; that is, how they are a conversational rather than a cognitive phenomenon.

Wooffitt draws his own earlier work (Wooffitt, 1992) in which he studied the organization of reports of 'anomalous events' (poltergeists, UFOs, and such). In particular, it analysed some of the ways in which speakers constructed reports of such events in ways that attend to a likely sceptical audience. It drew in turn on Sacks's (1984) classic work on the way people may 'do being ordinary' for particular purposes and on Jefferson's (forthcoming) development of this line of thinking. Wooffitt notes that when participants describe anomalous events they are (from a psychological perspective) recollecting those events; the descriptions can be studied as memories. 
Wooffitt picks out a number of features of these descriptions that might be relevant to cognitive research. For example, they commonly contain $\mathrm{X}-\mathrm{Y}$ constructions where the $\mathrm{X}$ is a description of the speaker's actions and $\mathrm{Y}$ is the report of the first awareness of the phenomenon:

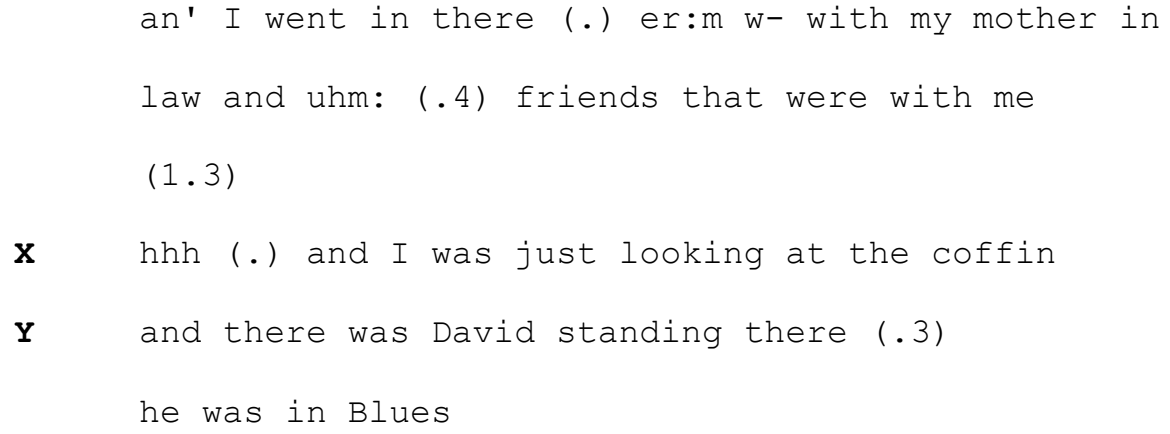

Wooffitt argues that the $\mathrm{X}$ part of these formulations works as a device designed to establish and display the mundane environment of the experience and the mundane orientation to it by the speaker. As the first part of a contrast it sets up, and highlights, the special or unusual nature of the Y component. It also displays what the speaker was not doing, that is hoping or waiting for something anomalous to happen, and thus perhaps displaying a out of the ordinary beliefs. For Wooffitt the point about this pragmatic organization of reports is that if we fail to grasp its practical and rhetorical orientation we may start to see it simply as the consequence of cognitive coding. So the idea that flashbulb memories encode mundane particulars in the brain, through some cognitive and neurological process, fails to consider that such particulars may be an artefact of reporting anomalous or dramatic events. More generally, Wooffitt argues for an enriched approach to human memory, less focused on its cognitive or neurological basis and more attentive to its pragmatics.

10. Lynch \& Bogen: My memory has been shredded.

Like Wooffitt, Lynch and Bogen focus on a phenomenon that cognitive psychologists would subsume under the category memory. While Wooffitt draws more directly on conversation 
analysis and the work of Sacks and Jefferson, Lynch and Bogen draw on ethnomethodology, and the work of Garfinkel as well as the broader tradition of linguistic philosophy. Like Coulter, they are less concerned to develop a dialogue or rapprochement with cognitive psychologists, than to rework everything. As they argue that they are not aiming to provide an alternative geography of cognition 'because the concept of 'cognition' itself is likely to be dissolved in the course of the displacement from an abstract space of mental representation to a contexture of communicative practices' (this volume, pp. **).

Lynch and Bogen's approach to 'cognitive' topics works with three intertwined strategies. First, select a cognitive science topic such as memory or perception, but located within a particular social setting. Second, consider how this topic becomes intelligible through actions and expressions that are bound to, and understandable within, interactional, pragmatic and political contexts. Third, provide an understanding of the available descriptions of cognitive events or processes in terms of their role in interaction.

Building on their influential study of national scandals, and Iran-Contra in particular (Lynch \& Bogen, 1996), they illustrate these basic strategies using the kinds of materials (senate hearings, recordings, documents) that those scandals have incidentally made available. For example, they examine the use of 'memory lapses' in Oliver North's contributions to the Iran-Contra investigation, and the way practices of shredding documents were developed to provide for 'plausible deniability' of key claims. North used 'I don't remember' in testimony so many times it came to be called the Contra-mantra. They show how his 'don't remember' responses had the virtue of defeating what McHoul (1987) calls the binary logic of yes-no questions. The problem with such questions is that either option can lead to further trouble. On the one hand, a 'yes' can implicate guilt. On the other, a denial is vulnerable to suggesting strategic dissembling if further contradictory evidence is produced. 
Lynch and Bogen focus in particular on the interactional logic that distinguishes 'I forgot' from 'I don't remember', noting that the former potentially concedes much more. They also discuss the role of the counterfactual conditional form of many memory claims in the testimony. These are claims of the form:

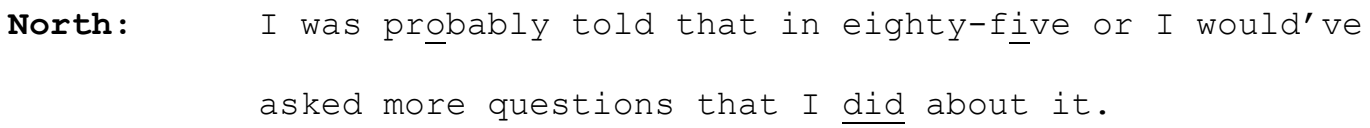

In this case, for example, North is able to present a failure to remember something as indicative that his was acting in an appropriate manner; that is, a manner that would be unremarkable and therefore unmemorable. They conclude:

The possibilities of remembering and forgetting are thus logically bound to assessments of particular persons and agent-categories, and are associated with judgments about plausibility and credibility and defences against accusation (this volume, pp. $\left.{ }^{* *}\right)$.

They are particularly pessimistic about any integration of this research with the domain of 'cognitive science', arguing instead that they are addressing topics in their home environment in a way that cognitive scientists have failed to do.

\section{Edwards \& Potter: Discursive psychology, mental states and descriptions.}

As we have noted above, Edwards and Potter have been developing a distinctive discursive psychological approach for over a decade, applied to 'psychological' topics such as memory, attribution, categories, scripts and so on (see Edwards, 1997; Edwards \& Potter, 1992, 1993). This chapter picks out some of the themes in this work as well as summarising its general programmatic features. It summarises three basic strands of DP work: (a) it has respecified and criticised mainstream cognitive research; (b) it has produced analytic studies of the psychological thesaurus, exploring the situated and rhetorical uses of psychological terms in 
peoples' talk; (c) it studies the way psychological themes and orientations are managed, whether psychological terms are used or not.

This chapter picks out strand $\mathrm{b}$ in particular, but simultaneously addresses the central DP issue of how descriptions of actions and events provide for psychological inferences. It deals variously with knowing and not knowing, telling, wanting, hoping, liking and not liking, and thinking. In each case, the aim is to show how the delicate situated rhetorical use of those psychological terms is bound up with the performance of practical actions. A particular theme of these analyses is to show that such terms cannot be understood as simply the expressions of mental states in the manner of telementation. They can thus be contrasted with cognitive science approaches that might look to treat such words as cognitive tokens.

DP can also be contrasted with a linguistic philosophical approach of the kind developed by Ryle and Wittgenstein and illustrated in this collection by Coulter. Part of this contrast is that DP does not attempt to show cognitivist understandings are incoherent or wrong, but rather to study their use as a practice within public forms of discourse (see Potter \& Edwards, 2003). People may talk on the 'proposed and oriented to basis, that their words are expressing inner thoughts and feelings' (this volume, pp. **) in clinical psychology, for example, or everyday settings. This becomes the analytic topic of DP. This special kind of 'indifference' is similar to that pressed by Lynch and Bogen, and by Wooffitt, although Wooffitt is more optimistic about the potential for fruitful dialogue with cognitive scientists, as are Edwards and Potter. 


\section{Issues and implications}

This collection includes a range of mature analyses of interaction. Although they take various positions on the status of cognition, and the different kinds of things cognition might be (if anything at all!) they offer very different kinds of analyses to those common in cognitive science. Even Sanders - who in terms of this collection is most directly sympathetic to the application of cognitive science ideas to interaction research -works with a style of analysis unusual in, maybe even antithetical to, the overwhelmingly experimental and conceptual modelling tradition of cognitive work. We will end this introduction and overview by highlighting a few of the issues and implications that will be addressed in different ways in the collection. Without attempting to be comprehensive we will address three themes raised by the chapters and ask more questions than we answer. We hope that readers can usefully hold these in mind while reading the chapters and perhaps return to them at the end.

\section{Plans, strategies and the language of mind}

We have already noted a tension between the model of cognitive processes as operating through a language of mind which is closely related to the folk psychology of desires, goals, plans and so on and the ethnomethodological approach to goals and plans that emphasizes their complex and often post hoc relation to practice. As we indicated in our discussion of Suchman's (1987) work, in the ethnomethodological picture plans are as much to do with accountability as they are causal templates driving action.

Hopper's paper attempts to address the issue of planning through a focus on process. Can we capture the working of planning in interaction through considering the procedures for receiving compliments? He searches for evidence that pre-strategies have been in operation 
in a series of such receipts. He asks if there is evidence that the speaker has strategically (in a consciously prepared way) thought out a modification of a compliment receipt to achieve a secondary purpose (e.g. to emphasize the theme of 'thrift' to key figures that will be politically important)? He shows that it is particularly difficult to analytically pin down the operation of such pre-strategies. Part of the difficulty is that any strategy will have to play out through the contingencies of interaction and work with socially established conversational procedures. Therefore if there is a strategy at work it has to be fluid and responsive.

This study raises as many deep questions as it answers. If it can be established that there may be pre-strategy at work, as Hopper asserts, this leaves the question of what the status of such a strategy is. The sort of evidence that is provided is of modifications to standard forms, or standard forms being organized to allow them to piggyback further actions. The implication is that the standard forms are automatic and strategy allows a further level of orchestration of the automatic forms, e.g. to build references to thrift into complement receipts. However, that does not demonstrate that such a 'higher order' plan was 'represented' in 'consciousness', perhaps in a propositional form, although it implies a picture of that kind. It clarifies the deep cognitive science question, because it directs research attention to particular phenomena, but it does not answer that question. For example, could we conceive the sorts of 'higher order' strategic 'thinking' suggested in Hopper's chapter to be itself standardized, more off-the-shelf than bespoke, not requiring a unique propositional solution but dependent on the kind of rich conversational learning history that a human would have who used talk as their major means of getting things done, day in day out, throughout their lives?

Pomerantz has a more developed cognitive ontology in her chapter, suggesting that understanding, aims and concerns can all, on occasion, be treated as cognitive phenomena 
that influence how a person selects and employs a specific practice. Although she argues effectively for the value of methods of stimulated recall in accessing such things and thereby contributing to improvements in practices, this does not in itself, show that such things are cognitive phenomena in the way that a cognitive psychologist might understand the term. To show that a concern can be usefully 'accessed' does not in itself show that the concern is a cognitive object, a combination of propositions and emotional colour perhaps, existing in a mental space (for a contrasting analysis of ‘concern’ see, Potter \& Hepburn, 2003).

Concerns, aims and understandings are vital parts of lay accounting and they may appear as such in the stimulated recall setting. That does not make their use in that methodological setting a merely descriptive one. Pomerantz argues that we should distinguish between a display of understanding, for example, and actual understanding. But even if this distinction can be sustained, it does not in itself show that understanding must be understood as a cognitive state (Coulter, 1979).

\section{Moments of Mind Reading}

Both Drew and, to a lesser extent, Heritage operate with a distinction between 'verbal conduct' and the speaker's 'cognitive state'. Plainly this distinction is fundamental for exploring the potential connection between this interactional research and research in cognitive science. However, is this distinction discovered in their material, or is it assumed? Is what Drew calls a 'cognitive state' the same thing as a cognitive scientist would mean by that term? We have described some of the variety of assumptions about cognitive state in section 3 above. Drew suggests, in a move similar that of Pomerantz, that the CA use of the term 'orient to' for characterizing certain features of conduct may be an (inexplicit) cognitive usage. That is, it may simply stand for a cognitive state. From this perspective when Emma orients to a delay in accepting an invitation as indicating that her invitation is going to be 
turned down, she is (mentally, internally) recognizing that the declination is coming (Drew, this volume, pp. **). The key point, though, is the status of such a recognition. Is it a word that is practically useful to explicate Emma's conduct (for example, the upgrading of the invitation with the provision of beer), or is it a conscious (or even unconscious) cognitive state? Does Drew analytically confirm the latter, or is the latter a plausible everyday characterization of what is going on in a culture that tends to offer cognitive characterizations of conduct?

Take the example of 'confusion', which is Drew's main topic. He brilliantly marshals the procedures and findings of CA to identify confusion in conduct. Most relevantly, his analysis attempts to identify confusion that is neither oriented to as such nor used as a resource. However, assuming that he has been successful in this task, does this success show that there is an associated cognitive state of confusion? Does everything that people do or show have an associated mental state? Is Drew discovering the presence and consequence of cognition or presupposing it?

Similar questions can be posed with respect to Heritage's analysis of oh-receipts and changes of state. His analysis skilfully delineates the various pieces of interactional work that 'oh' particles can perform. And he highlights various lines of interactional evidence that suggest that although 'oh' signals a change of state it does not necessarily accompany on a momentary basis a change in experience, or cognitive state, or neuropsychology.

The question that remains is whether some inner, psychologically represented change (in consciousness, or cognition, or neural states) takes place, whether yoked immediately to 'oh' or somewhat temporally disengaged. Does the existence of such a change require any specific cognitive analysis? Could 'change of state' be an interactionally inspired gloss on something that we can both access analytically, and recognise as language users, but not require that there is a difference in propositional representations embodied somewhere in 
neuroanatomy? Could it be equally compatible with some kind of yet to be fully developed connectionist account of competent conduct that requires no realized propositional representations? Indeed, could 'oh-receipts' and the 'changes of states' they signal be useful accounting devices primarily oriented to action, providing a neat, simplified practical way of displaying position change in interaction as an easily understood either/or?

However challenging these questions are for interaction analysis they are at least as challenging for cognitive science insofar as they incorporate either implicit or explicit theories of conduct. The beautifully realized analysis of Drew and Heritage identify phenomena of interaction that a comprehensive cognitive theory of action would need to account for and so far the image of conduct in cognitive science has tended to be abstract and simplified.

\section{The study of Mind in Action}

The possibility of creative debate between cognitive scientists and interaction researchers is an exciting one, and one we hope this collection encourages. As we have indicated, although potentially fruitful the dialogue will be a complex one. The differences are not just of theory and findings; they are about metatheoretical assumptions and methodological practices. For cognitive science researchers used to testing claims through experimental simulations or abstract programming exercises, the sorts of detailed, inductively based descriptive studies typical of conversation analysis and discursive psychology are likely to be hard to accommodate. Hopefully, this volume will highlight the value of taking this research seriously.

Nevertheless, it is likely that some of the interactional research will generate more critical tension with cognitive science work. At the level of theory, interactional research underscores difficulties with the idea of an actor as a socially isolated problem solver. Even 
the researchers in this collection who most fully embrace at least the principle of cognitive states and representations as a topic of study (Sanders, Pomerantz, Drew and, perhaps more cautiously, Heritage, Hopper and Schaeffer and Maynard) highlight just how far any potential cognitive analysis must take into account of socially shared and conventionalized procedures of interaction. At the level of method, different strands of interaction research in both CA and DP have highlighted the failures of cognitive science research to encompass the action orientation of talk in research settings. Schaeffer and Maynard provide an excellent example of this in their chapter. It may be that at least some of the inferences from cognitive research studies are artefacts of the failure to appreciate this action orientation (see Edwards, 1997).

Outside of these different kinds of engagement there is another possibility here developed most explicitly in Wooffitt, Lynch and Bogen, and Edwards \& Potter, and underscored by Coulter's critique of the very enterprise of cognitive science. This would involve the development of a field of study that would consider phenomena that had been subsumed into cognitive science from a practical and interactional perspective. It would consider both the (ostensibly) mental lexicon and its role in various mundane and institutional practices, and the way (purportedly) psychological issues (knowledge, accountability, attitude, stake and interest) figure within particular practices. This approach would be noncognitivist in that it would not attempt to explain conduct by reference to cognitive entities (such as knowledge, motive, attitudes and so on); those things would figure as topics of study. Whatever else they are, all of the contributions to this volume could be understood as contributions to such an enterprise. Whether it is called the sociology of mind, praxiology, discursive psychology or even social psychology (psychology in and for social practices why not?) such an interdiscipline has exciting prospects. 


\section{Acknowledgement}

We would like to thank Derek Edwards, Alexa Hepburn and Liz Stokoe for commenting on an earlier version of this chapter. 